\title{
Preparing planarian cells for high-content fluorescence microscopy using RNA in situ hybridization and immunocytochemistry
}

\author{
Markus A. Grohme ${ }^{1}$, Olga Frank ${ }^{1}$, Jochen C. Rink ${ }^{2 *}$ \\ ${ }^{1}$ Max Planck Institute for Molecular Cell Biology and Genetics, Pfotenhauerstrasse 108, \\ 01307 Dresden, Germany \\ ${ }^{2}$ Max Planck Institute for Biophysical Chemistry, Am Fassberg 11, 37077 Göttingen, \\ Germany \\ *: Correspondence: jochen.rink@mpibpc.mpg.de
}

This is a pre-print of a forthcoming chapter in the Methods in Molecular Biology volume "Schmidtea mediterranea: Methods and Protocols", edited by Luca Gentile, to be published by Springer.

\section{Abstract}

High-content fluorescence microscopy combines the efficiency of high-throughput techniques with the ability to extract quantitative information from biological systems. The planarian community has developed sensitive and robust assays for whole animals, yet cell based assays, despite their practical aspects, have not been explored to the same extent. Here we describe a modular collection of detailed protocols adapted for fixed planarian cells that enable multiplexed measurements of biomarkers in microwell plates. Methods include the detection of RNA transcripts by RNA fluorescent in situ hybridization combined with tyramide signal amplification using hapten-labeled riboprobes. In addition, immunocytochemical protocols for quantifying proliferating cells by the detection of phosphorylated histone $\mathrm{H} 3$ as well as 5-bromo-2'-deoxyuridine incorporation into the nuclear genome are described. The assays are compatible with planarians of virtually any size, as the tissue is disaggregated into a single cell suspension before fixation and staining. By sharing many reagents with established planarian whole mount staining protocols, preparation of samples for high-content microscopy adoption requires little additional investment. Recommendations for successful experimental workflows and common sources of errors are discussed.

Key words: planarian, maceration, high-content fluorescence microscopy, formaldehyde fixation, RNA FISH, immunocytochemistry, BrdU, phospho-histone 3, tyramide signal amplification

\section{Introduction}

Major technical advances in automated microscopy and image analysis have enabled screens for a wide range of visual phenotypes in cells and organisms using small molecule or RNAi-based perturbation approaches (Boutros, Heigwer, and Laufer 2015). High-content cell-based assays allow the parallel monitoring of multiple cellular phenotypes using dyes, antibodies or RNA/DNA probes at the (sub-)cellular level. Thus, they provide insight into the 
complexity of biological processes in both individual cells and on a population scale encompassing thousands of cells (Liberali et al. 2015).

The planarian community has developed a wide range of protocols and assays for planarian whole-mounts. Colorimetric and fluorescent whole mount in situ hybridization are popular techniques for localizing RNA expression patterns within planarian tissue. A general drawback of staining macroscopic organisms is the limited diffusion of reagents into the tissue, leading to experimental variability and misleading staining patterns. To overcome these limitations, staining can be performed on tissue sections (Solana 2018; Adell et al. 2018), although the cutting plane of a given cell might vary. Therefore, single cell assays allow the unequivocal assignment of staining patterns to distinct cells at (sub-)cellular resolution. In planarians, RNA fluorescence in situ hybridization (RNA FISH) or immuno-cytochemistry (ICC) on single cells have been described previously (Scimone et al. 2014; Newmark and Sánchez Alvarado 2000). The available protocols involve isolation of cells by fluorescence-activated cell sorting and/or fixation on coverslips, which is not practicable for high throughput analyses. In an attempt to streamline the staining and imaging of single planarian cells, we have combined chemical dissociation of planarian tissue with subsequent formaldehyde fixation in multi-well plates. Cell suspension are non-enzymatically generated using a "maceration solution" ${ }^{11}$ while retaining the composition of the original tissue (Newmark and Sánchez Alvarado 2000; David 1973). In its simplest form, maceration solution contains a mixture of acetic acid, glycerol and water, although several modified compositions exist (Schneider 1890; Baguñà 1976). Its utility has been recently rediscovered for single cell RNA sequencing applications (García-Castro et al. 2021). All subsequent stainings are thereby rendered agnostic to the dimensions of the original tissue, which abolishes many problems associated with riboprobe or antibody penetration. An early version of this method has been used to characterize components of the mitotic spindle checkpoint in the planarian Schmidtea mediterranea (Grohme et al. 2018). Building on the excellent protocols developed for RNA FISH in planarians and other organisms (Pearson et al. 2009; King and Newmark 2013; D. D. R. Brown and Pearson 2015; Lauter, Söll, and Hauptmann 2011), we have improved many aspects of sample preparation, storage and staining conditions for multi-well plates. Using the popular peroxidase-based tyramide signal amplification, transcripts over a wide range of expression abundances can be detected, generally on par with established whole mount protocols. The full procedure takes 2 to 6 days depending on the degree of target multiplexing and chosen incubation times. A typical result for a dual RNA FISH staining combined with phospho-histone 3 ICC staining is presented in Figure 1. While this method has been established using the planarian S. mediterranea, it should be transferable to other planarian species or soft organisms that can be easily disaggregated, including Hydra, for which the maceration solution was initially described (David 1973). We envision this method to be widely applicable for quantifying cell types and other cellular parameters. The flexibility and modularity of the plate format is ideal for high throughput screens, including the quantification of proliferation markers, counting cell numbers, screening hybridoma supernatants, or the optimization of antigen retrieval or blocking conditions. Potentially, it could serve as a complementary assay for the validation of single cell RNA sequencing experiments.

\footnotetext{
${ }^{1}$ This is an umbrella term and different compositions under the same name are in use in the field. We refer to the composition described by David (David 1973).
} 
A

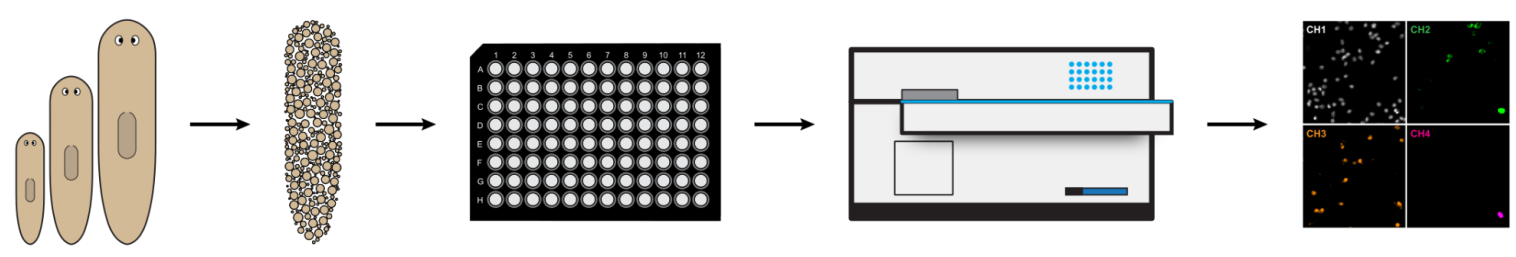

B

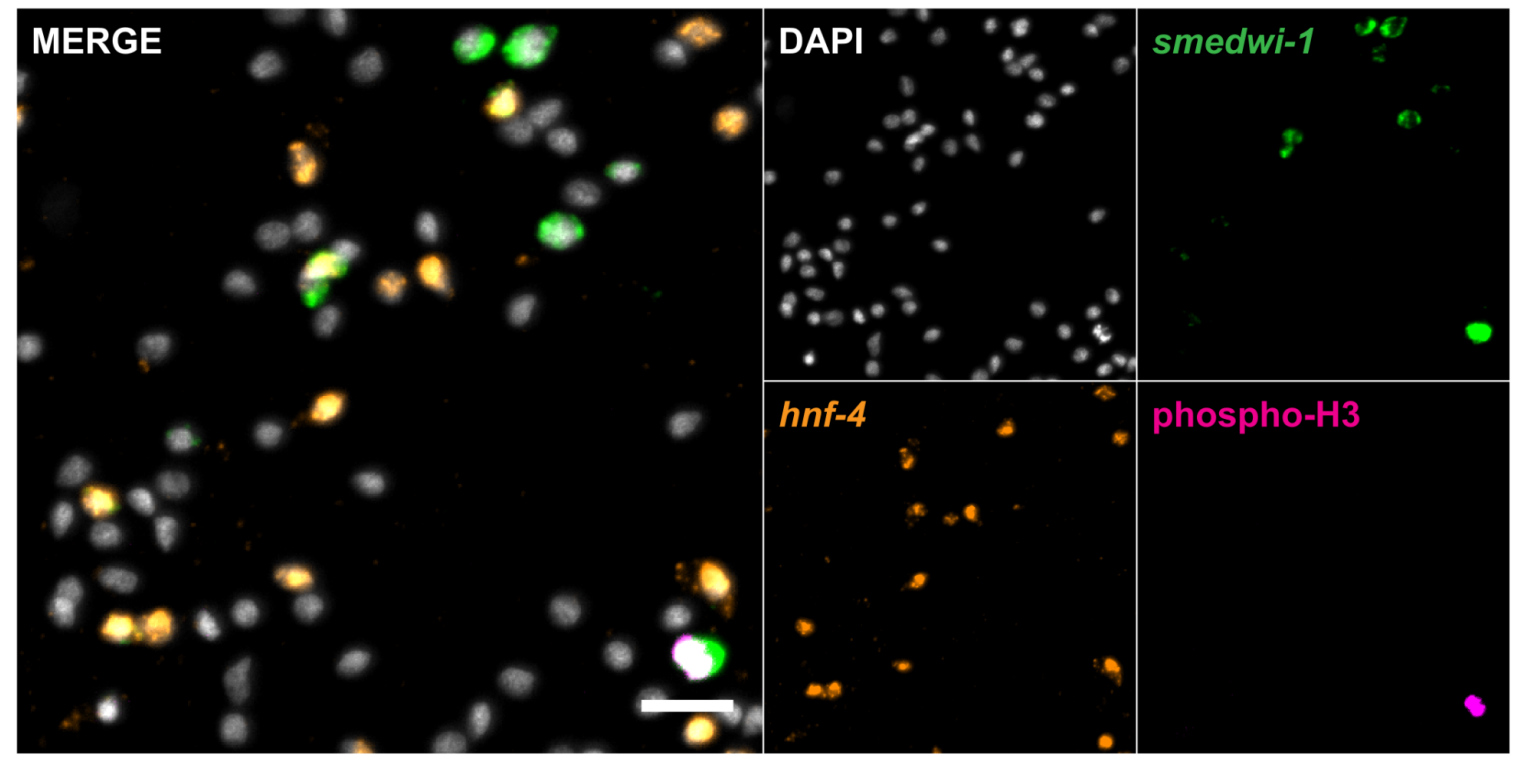

Fig. 1 Preparing planarian cells for high-content fluorescence microscopy

A) General workflow for preparing planarians for high-content imaging. Planarians of arbitrary size and experimental background are dissociated and transferred to microwell plates, fixed and stained using RNA-FISH or ICC. The plates are compatible with high-content imaging systems yielding multi-color fluorescence images. B) Multicolor epifluorescence images of macerated planarians with two-color FISH combined with ICC for phospho-H3 (S10/T11). DIG-labeled riboprobe against Smed hnf-4 and fluorescein-labeled riboprobe against smedwi-1 were developed using AF568-tyramide (orange) and fluorescein-tyramide (green), respectively. Cells in M-phase were detected using rabbit anti-phospho-H3 (S10/T11) and goat anti-rabbit Alexa 647-labeled secondary antibody (magenta). Nuclei were stained using DAPI (gray). Scale bar: $20 \mu \mathrm{m}$.

\section{Experimental considerations}

The various assays in this chapter are organized into modules and can be combined into single, dual or triple RNA FISH or a combination of FISH and immunocytochemistry (ICC) or ICC alone. In combined FISH and ICC experiments, the riboprobes should be developed before staining for other epitopes, due to the comparatively lower stability of RNA transcripts. A successful staining experiment is cumulatively affected by the purity of riboprobes, proper sample blocking and specificity of antibodies. Starting point for riboprobe synthesis are PCR products generated directly from gel purified amplicons or from cloned cDNA in a plasmid using a range of available haptens. This method chapter also includes protocols on how to store cell suspensions or cells fixed on plates for later analysis. Plates can be stored in an antifade medium and re-imaged at later time-points with no apparent loss of fluorescent signal. Supplementary protocols for the synthesis of hapten-conjugated riboprobes as well as for fluorophore-conjugated tyramides are also included. A short troubleshooting section 
can be found at the end of the chapter. Image acquisition, feature extraction and data analysis strategies have been described elsewhere in detail (Caicedo et al. 2016; Bougen-Zhukov et al. 2017; Caicedo et al. 2017).

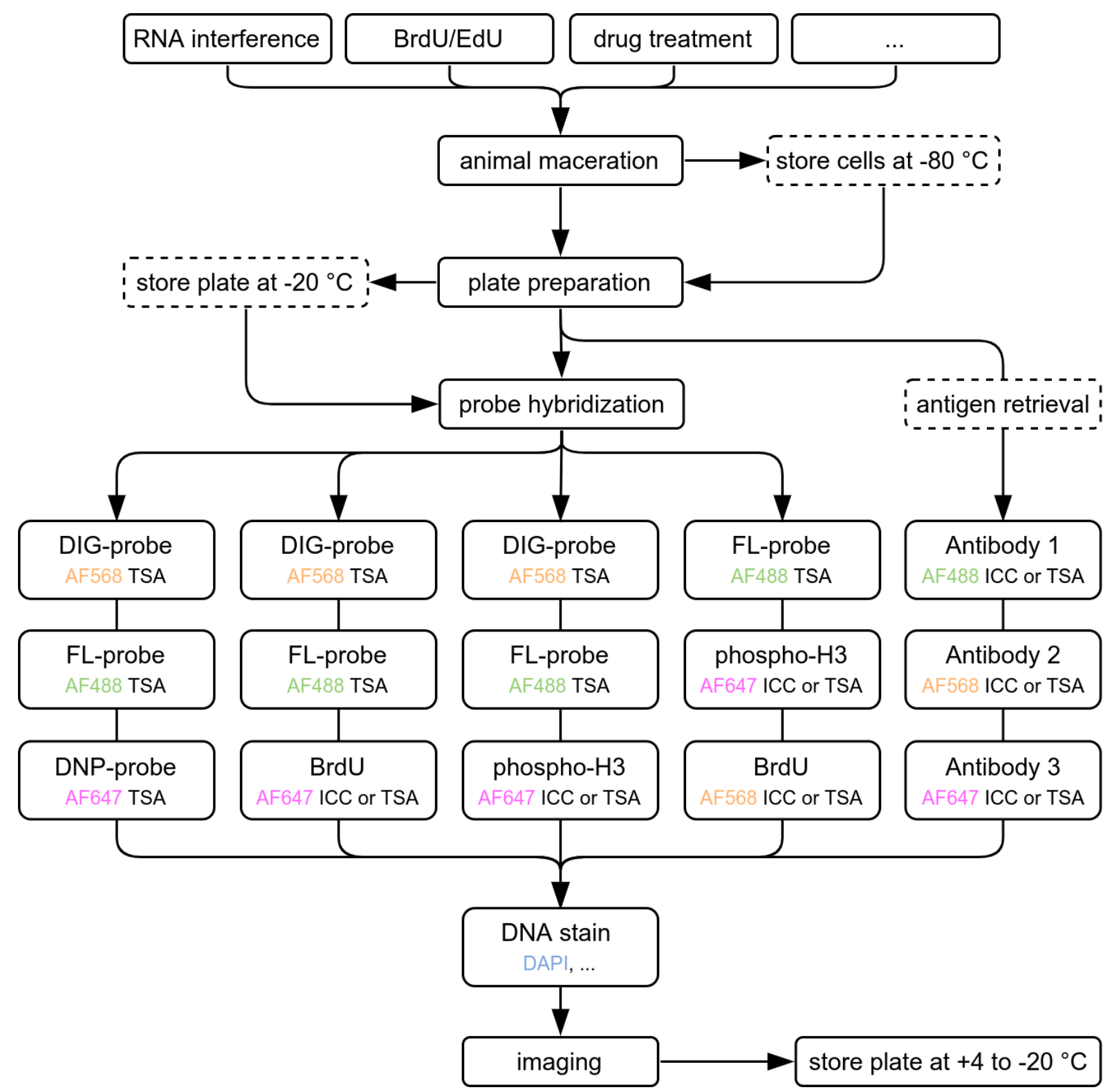

Fig. 2 Flowchart of potential applications and orders of staining for RNA FISH \& ICC on planarian cells

Input samples may originate from a wide range of experiments as long as they do not disrupt cellular integrity. Two major extended pause points are: storage of dissociated animals as cell suspension in glycerol at $-80^{\circ} \mathrm{C}$, or fixed and permeabilized cells in formamide-containing pre-hybridization buffer in multi-well plates at $-20{ }^{\circ} \mathrm{C}$. Examples of typical experimental workflows of $\mathrm{FISH}$ and $\mathrm{FISH}+\mathrm{ICC}$ combinations are presented. Optional steps are shown with a dashed outline. As a final step, nuclei are stained using a DNA-specific dye to quantify total cell numbers. Cells can be imaged or stored in an anti-fade medium. The figure was generated using draw.io-desktop (v14.6.13).

\section{Biological and staining controls}

Good controls are important for proper interpretation of any experiment. The simplest and most established approach in planarians is the depletion of transcripts or cell types using 
RNA interference (RNAi) (Rouhana et al. 2013; Newmark et al. 2003; Orii et al. 2003; Sánchez Alvarado and Newmark 1999). RNAi-treated samples can serve as negative biological controls in conjunction with sense riboprobes to control for signal specificity (see "Supplemental protocol: Riboprobe synthesis"). For establishing or troubleshooting RNA $\mathrm{FISH}$, strong and/or reasonably abundant positive control transcripts are e.g. Smed-agat1, Smed-gata4/5/6 or Smedwi-1 (Wagner, Wang, and Reddien 2011). For controlling staining consistency across plates, a large batch of a defined sample (starved, irradiated, or RNAi) can be prepared in advance and frozen in small aliquots to be included alongside experimental samples (see "Preparing macerated worms for storage").

\section{Animal state}

In general, starved animals ( $\geqslant 7 \mathrm{~d}$ ) show the cleanest signal and are a good background control to be included in an experiment. Feeding might increase background and unspecific binding of riboprobes and antibodies as a result of mucus production or other digestive processes. Furthermore, after excessive cell death of a given cell type (e.g. stem cell depletion), abundant transcripts (e.g. Smedwi-1) might still be detectable as speckles and cellular debris in the first few days. It is generally not recommended to include dyes for tracking RNAi food uptake (Rouhana et al. 2013; Hattori et al. 2018), as this will generate fluorescent background and/or stain unspecific structures such as lipid droplets.

\section{Sample preparation and pause points}

Although animal maceration, fixation, and staining can be performed on successive days, the protocol modularity offers some flexibility and contains two major potential pause points. Worms can be macerated in advance with excess glycerol and frozen in liquid nitrogen and stored at $-80{ }^{\circ} \mathrm{C}$ (see "Preparing macerated worms for storage"). This is helpful when many time-points or RNAi experiments are to be analyzed on a single plate, but parallel sample collection is logistically challenging or impossible. Furthermore, after formaldehyde fixation, the plates can be stored at $-20{ }^{\circ} \mathrm{C}$ in formamide-containing pre-hybridization buffer (see "Probe hybridization \& washing; Note 14"), which effectively protects cellular RNAs from degradation (Chomczynski 1992). This allows the preparation of plate copies from the same sample in advance, which can then be analyzed using different riboprobes or antibodies. Once hybridization of the riboprobes has been performed, pauses should be limited to a maximum of $1-2$ days at $4{ }^{\circ} \mathrm{C}$ in the dark until all riboprobes have been developed to limit potential RNA degradation by traces of RNAses. In contrast, immunocytochemistry is less critical and phospho-histone 3 ICC can be developed after some days of storage or extended primary antibody incubation at $4{ }^{\circ} \mathrm{C}$. The 96 -well polystyrene plates (Greiner Bio-One, Cat. No.: 655090) are certified for temperatures from $-20{ }^{\circ} \mathrm{C}$ to $+60{ }^{\circ} \mathrm{C}$ and are chemically resistant to formamide, which covers storage of the cells in the freezer and hybridization temperatures. We have not evaluated other plate manufacturers, so surface treatment and chemical stability might differ.

\section{Density of cell seeding}

The probability of identifying a cell type/state of interest largely depends on its abundance within the animal. While in starved $S$. mediterranea fewer than $1 \%$ of the cells are in M-phase (e.g. positive for histone $\mathrm{H} 3$ phosphorylated at serine 10), some abundant cells of interest can make up $10-20 \%$ of the animal (e.g. gut cells). A single 5-7 mm worm of $S$. 
mediterranea (CIW4 strain) contains $\sim 640,000-1,100,000$ cells (Thommen et al. 2019) and 1 $\mathrm{ml}$ of maceration solution will typically lead to an acceptable cell density. Plating $120 \mu \mathrm{l}$ of macerate per well in a 96-well plate is a good starting point for further optimizations. Generally, a density of $\sim 30$ cells per $100 \mu \mathrm{m}^{2}$ in the well is sufficient for most analyses. Overloading wells should be avoided, as cell clumps will lead to riboprobe and antibody trapping and complicates downstream automated image segmentation. Imaging of $\sim 2,000$ cells at independent positions in the well is sufficient for detecting most cell types, although capturing rare cells/events might require more cells.

\section{Fixation \& permeabilization}

For fixation we have not explored glutaraldehyde due to its well known autofluorescence generation (Collins and Goldsmith 1981). It has been shown that short RNAs such as miRNAs can be efficiently retained in tissue or in blotting applications after post-fixation with EDC (1-ethyl-3-(3-dimethylaminopropyl) carbodiimide) (Pall and Hamilton 2008; Pena et al. 2009). In our hands, EDC fixation completely abolished staining using tyramide signal amplification under our conditions. Staining strategies using EDC fixation might require different permeabilization steps or antigen retrieval, but these were not further explored. Compared to earlier versions of this protocol (Grohme et al. 2018), we have found that omission of Proteinase $\mathrm{K}$ treatment, which is a common source of batch to batch variability, does not negatively affect staining. This shortens the protocol and makes cell treatment less time critical and variable. Permeabilization is ensured by the inclusion of detergents in washing buffers and heating during riboprobe hybridization.

\section{Probe development, order of stainings, signal specificity}

Recipes for two alternative hybridization buffers ( $\mathrm{Hyb}$ and $\mathrm{Hyb}+$ ) and two tyramide signal amplification buffers (TSA and TSA+) are provided. Hyb+ is a slightly acidified ( $\mathrm{pH} \mathrm{6.0)}$ variation of $\mathrm{Hyb}$ (Thisse and Thisse 2008), as formamide becomes basic upon heating, which is detrimental to RNA stability. The $\mathrm{pH}$ of $\mathrm{Hyb}(\mathrm{pH} \mathrm{7.0)}$ or $\mathrm{Hyb}+(\mathrm{pH} \mathrm{6.0)}$ can be controlled through the $\mathrm{pH}$ of the SSC buffer or alternatively by acidification of already prepared $\mathrm{Hyb}(\mathrm{pH} 7.0)$ through addition $460 \mu \mathrm{l}$ of $1 \mathrm{M}$ citric acid solution for each $50 \mathrm{ml}$ of $\mathrm{Hyb}$. The standard TSA buffer gives good staining with a wide range of riboprobes without generating excessive background. TSA+ buffer generates a stronger signal from lower tyramide concentrations and might be a good choice when maximum sensitivity is required. Extensive tyramide signal development is a double-edged sword and might lead to unacceptable background for weak riboprobes, therefore proper antibody blocking and clean riboprobes are required. TSA+ seems to be largely safe for developing DIG-labeled riboprobes (see "Tyramide signal amplification - Digoxigenin riboprobe (DIG-probe)"). Riboprobes containing different haptens (DIG, Fluorescein, DNP) might behave differently and are not readily interchangeable as riboprobe and respective antibody affinity might differ. Figure 2 provides an overview and recommendations regarding the order of stainings or choice of fluorophores. In dual or triple FISH, weakly expressed targets should be developed first. It is generally advisable to develop the BrdU signal last, as the harsh antigen retrieval using $\mathrm{HCl}$ would likely affect most epitopes. For experiments involving BrdU detection, It is recommended to perform ICC (e.g. phospho-H3) in conjunction with tyramide deposition instead of fluorophore conjugated secondary antibodies as antibody complexes might dissociate during BrdU antigen retrieval. Some antibodies that work well in other applications 
(e.g. Western Blot or on methanol fixed cells), might not work anymore after maceration or in situ hybridization. Therefore, conditions for new antibodies should be tested individually. If the maceration solution destroys the target epitope, cell suspensions have to be prepared in a different way, e.g. mechanically (Fernandéz-Taboada et al. 2010) or enzymatically (Moritz et al. 2012; Wagner, Wang, and Reddien 2011; Reddien et al. 2005; Hayashi et al. 2006) and optionally flow sorted. The protocol then should start at the 4\% PFA in 1X PBS fixation step (see "Preparing the plate(s) and fixation of cells").

\section{Blocking the cells}

To prevent non-specific binding of probes and antibodies, samples can be blocked using a variety of protein or non-protein mixtures. Common blocking reagents are bovine serum album (BSA), gelatin (porcine or cold water fish), serum (calf, sheep, goat, horse, donkey), skim milk or purified casein. The type of blocking reagent should be optimized for each antibody or assay (Vogt et al. 1987; Hauri and Bucher 1986). For example, in the case of the commonly used anti-fluorescein antibody (Roche, Cat. No.: 11426346910), inclusion of porcine gelatin (Sigma, Cat. No.: G2500) suppressed non-specific binding, while cold water fish gelatin (Sigma, Cat. No.: G7765) at the same concentration did not. Non-protein blocking buffers often contain polyvinylpyrrolidone and detergents (Haycock 1993). For some phosphoprotein antibodies the Roche Western blocking reagent (Roche, Cat. No.: 11921673001), skim milk (which contain the phosphoprotein casein), or phosphate buffers in general might generate problems. Here, Tris based buffers are often recommended. Staining conditions have to be tested empirically, but fortunately the plate format allows rapid identification of optimal conditions. Optimizing the composition of PreHyb and HyB buffers for RNA FISH, which contain a number of different blocking reagents (Denhardt's Reagent, tRNA, heparin) is generally not necessary.

\section{Fluorophores and secondary antibodies}

Optimal combinations of fluorophores and light sources and detection systems should be chosen to maximize sensitivity and prevent signal bleed through. A common combination of DAPI, Alexa Fluor 488, Alexa Fluor 568 and Alexa Fluor 647 is spectrally well separated and compatible with most imaging setups. Although fluorophores emitting in blue/cyan are available (AMCA, Alexa Fluor 350, Alexa Fluor 405), this channel is generally reserved for nuclear DNA staining using DAPI (4',6-diamidino-2-phenylindole). As spatial resolution is lost after dissociation, a nuclear DNA marker is useful for discriminating between bona fide cells and debris, as well as to quantify total cell numbers. Nuclei are readily stained with dsDNA specific dyes in the blue/cyan spectrum (DAPI, Hoechst 33342, Nuclear Violet ${ }^{\mathrm{TM}}$ LCS1 or similar). Alternatively, DRAQ5 a far red emitting DNA dye can be used (Smith et al. 1999), although this sacrifices the channel with generally lower autofluorescence. For ICC, primary antibodies should be chosen from different species and fluorophore-conjugated secondary antibodies should be highly cross-adsorbed to minimize non-specific binding. If two or more murine monoclonal antibodies belong to different lgG subclasses, staining with IgG subclass specific secondary antibodies is possible (Manning, Bundros, and Trimmer 2012). Mice express 4 of the 5 available $\lg G$ subclasses, which typically encode for $\lg G 1, \lg G 2 b$ and IgG3, and depending on their strain will also express either IgG2a (BALB/c and Swiss Webster) or IgG2c (C57BI/6, C57BI/10, SJL and NOD strain) (Martin, Brady, and Lew 1998); (Collins 2016). We have successfully used murine IgG1 and IgG2a primary antibodies with 
subclass specific secondary antibodies and found their performance comparable to multi-species detection setups e.g. murine vs rabbit primary and secondary antibodies.

\section{Antigen retrieval for Immunocytochemistry}

Some antibodies might require antigen retrieval, and in pure ICC experiments (without hybridization), the mild conditions employed might leave antigens masked. There is a wide range of antigen retrieval techniques employed in the histology field. We have had success with chemical antigen retrieval strategies, including $0.1 \%(\mathrm{w} / \mathrm{v})$ sodium dodecyl sulfate (SDS) (D. Brown et al. 1996), $6 \mathrm{M}$ urea (Hausen and Dreyer 1982) or $6 \mathrm{M}$ guanidine hydrochloride (Peränen, Rikkonen, and Kääriäinen 1993). Treatment for 30 min at RT was generally sufficient to improve staining. Heat induced antigen retrieval has also been described for planarians (King and Newmark 2013), which we have not explored. Some antibodies work better after post-in situ hybridization, such as the anti-BrdU antibody (clone Bu20a). If RNA-FISH is not required, a shorter mock in situ hybridization without riboprobes can act as a mild antigen retrieval step in place of the full protocol.

\section{Storage of stained cells in plates}

After samples have been labeled with fluorophores, they should be protected from light during all subsequent washing, incubation steps and during long-term storage to prevent fluorophore bleaching. The plate lid can be covered with adhesive aluminum foil to protect the samples from light (e.g. $3 \mathrm{M}^{\mathrm{TM}}$ Aluminium Foil Tape 431). For short-term storage of stained cells (days to a week), the plates can be kept at $4{ }^{\circ} \mathrm{C}$, protected from light. To prevent evaporation cells should be kept in buffered glycerol medium or a glycerol-based anti-fade storage medium to prevent fluorophore bleaching (see "Buffers \& solutions"). Both DABCO and sodium azide are singlet oxygen quenchers and used as anti-fade reagents (Johnson et al. 1982; Langanger, De Mey, and Adam 1983; Ouannes and Wilson 1968), although the main function of the latter is to prevent bacterial growth. An alternative popular anti-fading reagent is n-propyl gallate, which we have not tested (Giloh and Sedat 1982; Johnson et al. 1982; Langanger, De Mey, and Adam 1983). Plates sealed with adhesive PCR plate seals and stored this way at $4{ }^{\circ} \mathrm{C}$ and protected from light can be re-imaged after several months without obvious loss of signal.

\section{Equipment \& Materials}

Equipment should be clean to prevent contamination by microorganisms or exogenous enzymes, especially RNAses (e.g. from plasmid isolation buffers). Stocks of buffers and solutions should be prepared using RNAse-free $\mathrm{H}_{2} \mathrm{O}$ and disposable filter-pipette tips. In our hands, autoclaved de-ionized water $\mathrm{H}_{2} \mathrm{O}$ is sufficiently pure, but if problems persist, treatment of $\mathrm{H}_{2} \mathrm{O}$ with $0.1 \%(\mathrm{v} / \mathrm{v})$ diethylpyrocarbonate might be required (Wolf et al. 1970).

\section{Equipment}

- Centrifuge with swing-out rotor and plate adaptors, coolable (any supplier).

- Centrifuge with fixed-angle rotor for $1.5 \mathrm{ml}$ tubes, coolable (any supplier). 
- Multipette M4 repeating pipette (Eppendorf, Cat. No. 4982000012) or similar (Multipette plus)

- Disc-rotator for $1.5 / 2.0 \mathrm{ml}$ tubes

- 8 or 12 multichannel pipette

- Vacuum pump and collection bottle

- Hybridization oven

- Rocking shaker

\section{Reagents \& Consumables}

- Adhesive PCR plate seals (ThermoFisher Scientific, Cat. No.: AB0558)

- N-Acetyl-L-cysteine (MW: 163.19, CAS: 616-91-1) (Sigma, Cat. No.: A7250 / Carl Roth, Cat. No.: 4126). Store at $4{ }^{\circ} \mathrm{C}$.

- Boric acid (MW: 61.83, CAS: 10043-35-3) (Carl Roth, Cat. No.: 6943.2)

- 96-well plates (F-bottom / chimney well, $\mu$ Clear® bottom, black, cell culture treated, sterile, with lid; Greiner Bio-One, Cat. No.: 655090)

- CellTrics ${ }^{\circledR} 50$ um cell strainer (yellow; Sysmex, Cat. No.: 04-0042-2317)

- Citric acid monohydrate (MW 210.14, CAS: 5949-29-1) (Sigma, Cat. No.: 33114-500G)

- DABCO (1,4-diazabicyclo[2.2.2]octane) (MW: 112.17, CAS: 280-57-9) (Sigma, Cat. No.: D27802)

- Dextran sulfate sodium salt from Leuconostoc spp. (MW: >500,000, CAS: 9011-18-1) (Sigma, Cat. No.: D8906). Store at $4^{\circ} \mathrm{C}$.

- 50X Denhardt's solution (Alfa Aesar, Cat. No.: J63135.AE). Store at $-20^{\circ} \mathrm{C}$.

- 1,4-Dithiothreitol (DTT) (MW: 154.2, CAS: 3483-12-3) (Carl Roth, Cat. No.: 6908.1 or 6908.2 or 6908.3 or 6908.4$)$

- Dimethyl sulfoxide (DMSO) (MW: 78.13, CAS: 67-68-5) (Sigma, Cat. No.: 276855-100ml)

- N-N-Dimethylformamide (anhydrous, MW: 73.09, CAS: 68-12-2) (Sigma, Cat. No.: 227056-100ml)

- $16 \%$ Formaldehyde (Electron Microscopy Sciences, Cat. No.: 15710 or 15711)

- Formamide (deionized for molecular biology, MW: 45.04, CAS: 75-12-7) (Applichem, Cat. No.: A2156.0500)

- Gelatin from porcine skin (gel strength 300, Type A, CAS: 9000-70-8) (Sigma, Cat. No.: G2500)

- Glacial acetic acid (MW: 60.052, CAS: 64-19-7) (Carl Roth, Cat. No.: 3738.4)

- Glycerol ( $\geq 99.5 \%$, MW: 92,09, CAS: 56-81-5) (VWR, Cat. No.: 24388.295)

- Glycine (MW: 75.07, CAS: 56-40-6) (Sigma, Cat. No.: 50046-50G)

- Goat Serum (Thermo Scientific, Cat. No.: 16210064)

- Heparin (CAS: 9041-08-1) (Sigma, Cat. No.: H3393-250KU). Prepare 10 mg/ml Heparin in $\mathrm{H}_{2} \mathrm{O}$, filter with $0.22 \mu \mathrm{m}$ and store at $-20^{\circ} \mathrm{C}$.

- Horse Serum (Sigma, Cat. No.: H1138)

- Hydrogen peroxide (30 \% (w/w) in H2O, contains stabilizer, MW: 34.01, CAS: 7722-84-1) (Sigma, Cat. No.: H1009-100ML)

- 4-lodophenylboronic acid (MW: 247.83, CAS: 5122-99-6) (Sigma, Cat. No.: 471933-5G)

- Reagent reservoir with divider (ThermoFisher Scientific, Cat. No.: 95128095) 
- Roche Western Blocking Reagent (10\% purified casein protein in maleic-acid buffer; Roche, Cat. No.: 11921673001)

- SSC Buffer 20x Concentrate (pH 7.0; Sigma, Cat. No.: S6639)

- Sodium azide (MW: 65.01, CAS: 26628-22-8) (Sigma Cat. No.: S2002)

- Sodium hydroxide solution (1M, MW: 40.00, CAS: 1310-73-2) (Sigma Cat. No.: 1370311002)

- Syringe filter (PES, $0.22 \mu \mathrm{m}$; Millipore, Cat. No.: SLGP033RS / SLMP025SS or respective PVDF membranes)

- Yeast RNA (100 g, Roche, Cat. No.: 10109223001). Store at $-20^{\circ} \mathrm{C}$.

- Tween-20 (MW: 1,227.54, CAS: 9005-64-5) (Sigma, Cat. No.: P9416)

- Tris base (MW: 121.14, CAS: 77-86-1) (Carl Roth, Cat. No.: AE15.1 or AE15.2)

- Sodium citrate tribasic dihydrate (MW 294.12, CAS: 6132-04-3) (Sigma, Cat. No.: C8532-500G)

\section{Optional}

1. $3 \mathrm{M}^{\mathrm{TM}}$ Aluminium Foil Tape 431(Silver, $75 \mathrm{~mm} \times 55 \mathrm{~m}, 0.09 \mathrm{~mm}$ ) (3M, ID: 7100041791)

2. Gelatin from cold water fish skin (40-50\% in $\mathrm{H}_{2} \mathrm{O}$, CAS: $\left.9000-70-8\right)$ (Sigma, Cat. No.: G7765)

3. Liquid nitrogen (any supplier)

4. Well plate stand (Sigma, Cat. No.: W0765-1EA)

5. 384-well plates ( $F$-bottom / chimney well, $\mu$ Clear ${ }^{\circledR}$ bottom, black, cell culture treated, sterile, with lid) (Greiner Bio-One, Cat. No.: 781090)

\section{Nuclear DNA dyes}

Dissolving dyes in a mixture of equal parts DMSO and water will allow storage at $-20{ }^{\circ} \mathrm{C}$ in liquid form as this eutectic mixture displays a strong freezing point depression (Havemeyer 1966) and works well for e.g. Hoechst 33342 hydrochloride.

- DAPI (1 mg/ml in $\mathrm{H}_{2} \mathrm{O}$, MW: 350.25, CAS: 28718-90-3) (Thermo Fisher Scientific, Cat. No.: D1306) $\left(\mathrm{Ex}_{\max } 358, \mathrm{Em}_{\max } 461 \mathrm{~nm}\right)$

- DRAQ5 (5 mM in $\mathrm{H}_{2} \mathrm{O}$, MW: 412.54, CAS: 252903-95-0) (AAT Bioquest, Cat. No.: 17558) $\left(E x_{\max } 646, \mathrm{Em}_{\max } 697 \mathrm{~nm}\right.$, intercalated into dsDNA). Please note that azide interferes with DRAQ5 staining.

- Hoechst 33342 hydrochloride (1 mg/ml in $\mathrm{H}_{2} \mathrm{O}, \mathrm{MW}$ : 561.9, CAS: 23491-52-3)

(Thermo Fisher Scientific, Cat. No.: H1399) (Ex $x_{\max } 350, \mathrm{Em}_{\max } 461 \mathrm{~nm}$ )

- Nuclear Violet ${ }^{\mathrm{TM}}$ LCS1 (5 mM in DMSO) (AAT Bioquest, Cat. No.: 17543) (Ex $x_{\max } 401$, $\left.\mathrm{Em}_{\max } 460 \mathrm{~nm}\right)$.

\section{Primary antibodies}

- Anti-Phospho-Histone H3 (phospho S10 + T11, rabbit pAB [E173]) (Abcam, Cat. No.: ab32107). Use at 1:1,000. (Alternatives: Cell Signaling Technology, rabbit mAb, Cat. No.: 3377 or Cat. No.: 53348. Use at 1:1,000).

- Anti-BrdU antibody, rat [BU1/75 (ICR1)], (Abcam, Cat. No.: ab6326)

- Anti-BrdU antibody, mouse lgG1 [Bu20a], (Magaud et al. 1989), available from various vendors. Use at 1:1,000 $(2 \mu \mathrm{g} / \mathrm{ml})$. 


\section{Secondary antibodies}

RNA-FISH, tyramide signal amplification

- Anti-DIG-POD (Roche, Cat. No.: 11207733910). Store at $4^{\circ} \mathrm{C}$.

- Anti-Fluorescein-POD (Roche, Cat. No.: 11426346910). Store at $4^{\circ} \mathrm{C}$.

- Anti-DNP-POD (PerkinElmer, Cat. No.: FP1128). Store at $4^{\circ} \mathrm{C}$. Alternatively, SYnAbs S.A. (Gosselies, Belgium) has a range of anti-DNP antibody clones raised in mouse or rat hosts, which can be ordered as POD-conjugates.

\section{ICC, fluorphore-conjugated secondary antibodies}

- Goat anti-Mouse IgG (H+L), Alexa Fluor 488 (Thermo Fisher Scientific, Cat. No.: A-11001)

- Goat anti-Rabbit IgG (H+L), Alexa Fluor 555 (Thermo Fisher Scientific, Cat. No.: A-21429)

- Goat anti-Mouse lgG (H+L) Alexa Fluor Plus 555 (Thermo Fisher Scientific, Cat. No.: A-A32727)

- Goat anti-Mouse IgG (H+L) Alexa Fluor 568 (Thermo Fisher Scientific, Cat. No.: A-11004)

- Goat anti-Rabbit IgG (H+L), Alexa Fluor 647 (Thermo Fisher Scientific, Cat. No.: A-21245)

- Goat anti-Rabbit IgG (H+L) Alexa Fluor Plus 647 (Thermo Fisher Scientific, Cat. No.: A32733)

- ICC, IgG-subclass fluorphore-conjugated secondary antibodies

- Goat anti-Mouse IgG1 Cross-Adsorbed Secondary Antibody, Alexa Fluor 568 (Thermo Fisher Scientific, Cat. No.: A-21124)

- Goat anti-Mouse IgG2a Cross-Adsorbed Secondary Antibody, Alexa Fluor 647 (Thermo Fisher Scientific, Cat. No.: A-21241)

\section{ICC, tyramide signal amplification}

- Donkey anti-Mouse lgG $(\mathrm{H}+\mathrm{L}) \mathrm{F}(\mathrm{ab})_{2}$ Fragment, Peroxidase (Jackson ImmunoResearch, Cat. No.: 715-036-151)

- Donkey anti-Rabbit IgG $(\mathrm{H}+\mathrm{L}) \mathrm{F}(\mathrm{ab})_{2}$ Fragment, Peroxidase (Jackson ImmunoResearch, Cat. No.: 711-036-152)

- Donkey anti-Rat IgG $(\mathrm{H}+\mathrm{L})$, Peroxidase (Jackson ImmunoResearch, Cat. No.: 712-035-153)

\section{Buffers \& solutions}

10X Phosphate buffered saline (10X PBS) (1.37 M NaCl, $27 \mathrm{mM} \mathrm{KCl,} 100 \mathrm{mM} \mathrm{Na} \mathrm{HPO}_{4}$, $18 \mathrm{mM} \mathrm{KH}_{2} \mathrm{HPO}_{4}$ ) (1 L). Dissolve $80 \mathrm{~g}$ of $\mathrm{NaCl}, 2 \mathrm{~g}$ of $\mathrm{KCl}, 2.4 \mathrm{~g}$ of $\mathrm{KH}_{2} \mathrm{PO}_{4}$ (monobasic), $14.4 \mathrm{~g}$ of $\mathrm{Na}_{2} \mathrm{HPO}_{4}$ (dibasic) and fill up with deionized $\mathrm{H}_{2} \mathrm{O}$ to $1 \mathrm{~L}$. The $\mathrm{pH}$ of the $10 \mathrm{X}$ stock will be approximately 6.8 , but when diluted to $1 \mathrm{X}$ PBS the $\mathrm{pH}$ should change to 7.4. Adjust $\mathrm{pH}$ to 7.4 using $\mathrm{HCl}$ and sterile filter $(0.22 \mu \mathrm{m})$. 
1X PBSTx0.1 (1 L). Dissolve $10 \mathrm{ml}$ of Triton X-100 in $1 \mathrm{~L}$ of $10 X$ PBS. Dilute $100 \mathrm{ml}$ of $10 \mathrm{X}$ PBSTx 1 with $900 \mathrm{ml}$ deionized $\mathrm{H}_{2} \mathrm{O}$ for $1 \mathrm{~L}$ of PBSTx01. Note: Triton X-100 dissolves faster in $10 X$ PBS than in $1 X$ PBS.

$1 \%(w / v)$ gelatin from pig skin in $1 \mathrm{X}$ PBSTx0.1. Dissolve $1 \mathrm{~g}$ of gelatin from porcine skin (gel strength 300 , Type A) in $100 \mathrm{ml}$ of $1 X$ PBSTx0.1 and heat to $50^{\circ} \mathrm{C}$ in a water bath until the gelatin is completely dissolved. Aliquot and store at $-20{ }^{\circ} \mathrm{C}$. After thawing an aliquot, briefly heat to $30^{\circ} \mathrm{C}$ for 5 minutes to solubilize the gelatin and let cool to RT before dilution.

15\% PFA/1X PBS. Add 1/10th volume of 10X PBS to 16\% EM-grade PFA. Prepare fresh.

4\% PFA/1X PBS. Dilute 0.25 volumes of $16 \%$ EM-grade PFA with 0.1 volumes of $10 X$ PBS and fill up with deionized $\mathrm{H}_{2} \mathrm{O}$. Prepare fresh.

$2 \mathrm{~N} \mathrm{HCl}(12 \mathrm{ml})$. To $10 \mathrm{ml}$ of deionized $\mathrm{H}_{2} \mathrm{O}$ add $2 \mathrm{ml}$ of $37 \% \mathrm{HCl}(12 \mathrm{~N})$. Wear protective glasses and a lab coat! Prepare in that order under the fume hood (first water, then acid). The mixture will heat up and has to be cooled to RT before use. Prepare fresh.

1X PBSTx0.1, $25 \mathrm{mM}$ sodium azide in $(\mathbf{1 0 0} \mathrm{ml})$. Dissolve $162.5 \mathrm{mg}$ sodium azide in $100 \mathrm{ml}$ of $1 \mathrm{X}$ PBSTx0.1. Store at $4{ }^{\circ} \mathrm{C}$. Sodium azide is highly toxic! Prevent contact with skin!

1X Tris-buffered saline (1X TBS) $(50 \mathrm{mM}$ Tris-Cl, pH 7.5, $150 \mathrm{mM} \mathrm{NaCl})(1 \mathrm{~L})$. Dissolve $6.05 \mathrm{~g}$ of Tris base and $8.76 \mathrm{~g}$ of $\mathrm{NaCl}$ in $800 \mathrm{~mL}$ of deionized $\mathrm{H}_{2} \mathrm{O}$. Adjust $\mathrm{pH}$ to 7.5 with $1 \mathrm{M}$ $\mathrm{HCl}$ and fill up to $1 \mathrm{~L}$ with deionized $\mathrm{H}_{2} \mathrm{O}$.

DTT in $\mathrm{H}_{2} \mathrm{O}(1 \mathrm{M})(10 \mathrm{ml})$. Dissolve $1.54 \mathrm{~g}$ of DTT in $8 \mathrm{~mL}$ of deionized $\mathrm{H}_{2} \mathrm{O}$. Adjust the total volume to $10 \mathrm{ml}$. Prepare $1 \mathrm{ml}$ aliquots and store them at $-20^{\circ} \mathrm{C}$.

$\mathrm{NaCl}(3 \mathrm{M})(100 \mathrm{ml})$. Dissolve $17.532 \mathrm{~g}$ of $\mathrm{NaCl}$ in deionized $\mathrm{H}_{2} \mathrm{O}$ and fill up to $100 \mathrm{ml}$.

Maceration solution (glycerol, glacial acetic acid and $\mathrm{H}_{2} \mathrm{O}$ at a ratio of $\left.1: 1: 13\right)(45 \mathrm{ml})$. For $45 \mathrm{ml}$ prepare: $3 \mathrm{~g}$ glycerol (by weight), $3 \mathrm{ml}$ acetic acid, top up with deionized $\mathrm{H}_{2} \mathrm{O}$. Invert tube or place on rotator until glycerol is fully mixed. Store at $4{ }^{\circ} \mathrm{C}$ and chill on ice before use.

Maceration dilution solution, glycerol-free (glacial acetic acid and $\mathrm{H}_{2} \mathrm{O}$ at a ratio of 1:13) $(42 \mathrm{ml})$. To $39 \mathrm{ml}$ deionized water add $3 \mathrm{ml}$ glacial acetic acid. Store at $4{ }^{\circ} \mathrm{C}$ and chill on ice before use.

Quenching buffer (1X TBS, $0.2 \%$ (w/v) glycine, $25 \mathrm{mM}$ sodium azide) (100 ml). Dissolve $200 \mathrm{mg}$ of glycine and $162.5 \mathrm{mg}$ of sodium azide in $100 \mathrm{ml}$ of $1 \mathrm{X}$ TBS. Store at $4{ }^{\circ} \mathrm{C}$. Sodium azide is highly toxic! Prevent contact with skin!

20X SSC, pH 6.0 (3 M NaCl, 300 mM Na-citrate, pH 6.0) (500 ml). Dissolve $87.65 \mathrm{~g}$ of $\mathrm{NaCl}, 2.9945 \mathrm{~g}$ of citric acid monohydrate, $18.309 \mathrm{~g}$ of trisodium citrate dihydrate in a final volume of $500 \mathrm{ml}$ of deionized $\mathrm{H}_{2} \mathrm{O}$.

0.2X SSCTx0.1 and 2X SSCTx0.1 (1 L). For $0.2 X$ SSCTX0.1 mix $10 \mathrm{ml}$ of $20 \times$ SSC, $10 \mathrm{ml}$ of $10 \%(\mathrm{v} / \mathrm{v})$ Triton X-100 and $980 \mathrm{ml}$ of deionized $\mathrm{H}_{2} \mathrm{O}$. For $2 \mathrm{X}$ SSCTx0.1 mix $100 \mathrm{ml}$ of 20X SSC, $10 \mathrm{ml}$ of $10 \%(\mathrm{v} / \mathrm{v})$ Triton $\mathrm{X}-100$ and $890 \mathrm{ml}$ of deionized $\mathrm{H}_{2} \mathrm{O}$. 
WashHyb (50\% (v/v) formamide, 0.5\% (v/v) Tween-20, 5 X SSC, 1X Denhardt's solution) (1 L). Use a complete fresh $500 \mathrm{ml}$ bottle of deionized formamide, $50 \mathrm{ml}$ of $10 \%(\mathrm{v} / \mathrm{v})$ Tween-20, $250 \mathrm{ml}$ of $20 \mathrm{XSSC}$ (pH 6.0 or 7.0 ), $20 \mathrm{ml}$ of $50 \mathrm{X}$ Denhardt's solution and $180 \mathrm{ml}$ of deionized $\mathrm{H}_{2} \mathrm{O}$. Store $-20{ }^{\circ} \mathrm{C}$.

PreHyb (50\% (v/v) formamide, 1\% (v/v) Tween-20, 5X SSC, 1X Denhardt's solution, 100 $\mu \mathrm{g} / \mathrm{\mu l}$ heparin, $1 \mathrm{mg} / \mathrm{ml}$ yeast RNA, $50 \mathrm{mM}$ DTT) (1 L). Use a complete fresh $500 \mathrm{ml}$ bottle of deionized formamide, $100 \mathrm{ml}$ of $10 \%(\mathrm{v} / \mathrm{v})$ Tween-20, $250 \mathrm{ml}$ of 20X SSC (pH 6.0 or 7.0), $20 \mathrm{ml}$ of $50 X$ Denhardt's solution, $10 \mathrm{ml}$ of $10 \mathrm{mg} / \mathrm{mL}$ heparin, $1 \mathrm{~g}$ of yeast RNA, $7.7 \mathrm{~g}$ of DTT and add deionized $\mathrm{H}_{2} \mathrm{O}$ to 1 liter. Add DTT, last as it will oxidize over time. Store $-20{ }^{\circ} \mathrm{C}$.

Hyb $(50 \%$ (v/v) formamide, 1\% (v/v) Tween-20, 5X SSC, 1X Denhardt's solution, 100 $\mu \mathrm{g} / \mu \mathrm{l}$ heparin, $0.25 \mathrm{mg} / \mathrm{ml}$ yeast RNA, $50 \mathrm{mM}$ DTT, $5 \%$ (w/v) dextran sulfate) $(1 \mathrm{~L})$. Use a complete fresh $500 \mathrm{ml}$ bottle of deionized formamide, $100 \mathrm{ml}$ of $10 \%(\mathrm{v} / \mathrm{v})$ Tween-20, 250 $\mathrm{ml}$ of 20X SSC (pH 6.0 or 7.0 ), $20 \mathrm{ml}$ of $50 X$ Denhardt's solution, $10 \mathrm{ml}$ of $10 \mathrm{mg} / \mathrm{ml}$ heparin, $250 \mathrm{mg}$ of yeast RNA, $7.7 \mathrm{~g}$ of DTT, $50 \mathrm{~g}$ of dextran sulfate and add deionized $\mathrm{H}_{2} \mathrm{O}$ to $1 \mathrm{~L}$. Add DTT last, as it will oxidize over time. Make sure the dextran goes completely into solution. Store in aliquots of $50 \mathrm{ml}$ at $-20^{\circ} \mathrm{C}$.

TSA buffer ( $2 \mathrm{M} \mathrm{NaCl}, 0.1 \mathrm{M}$ boric acid, pH 8.5) $(200 \mathrm{ml})$. Dissolve $1.24 \mathrm{~g}$ of boric acid, $23.38 \mathrm{~g} \mathrm{NaCl}$ in $\mathrm{H}_{2} \mathrm{O}$. Adjust $\mathrm{pH}$ to 8.5 using $1 \mathrm{M} \mathrm{NaOH}$ and fill up to $200 \mathrm{ml}$ with deionized $\mathrm{H}_{2} \mathrm{O}$. Store at $4^{\circ} \mathrm{C}$.

TSA+ buffer (2 M NaCl, $0.1 \mathrm{M}$ boric acid, pH 8.5, $2 \%(\mathrm{w} / \mathrm{v})$ dextran sulfate, $0.1 \%(\mathrm{v} / \mathrm{v})$ Tween-20) $(200 \mathrm{ml})$. Dissolve $1.24 \mathrm{~g}$ of boric acid, $23.38 \mathrm{~g}$ of $\mathrm{NaCl}$ in deionized $\mathrm{H}_{2} \mathrm{O}$. Slowly add $4 \mathrm{~g}$ of dextran sulfate while stirring (takes time to dissolve). Adjust $\mathrm{pH}$ to 8.5 using $1 \mathrm{M}$ $\mathrm{NaOH}$. Add $2 \mathrm{ml}$ of $10 \%(\mathrm{v} / \mathrm{v})$ Tween-20 and fill up to $200 \mathrm{ml}$ with deionized $\mathrm{H}_{2} \mathrm{O}$. Store at $4^{\circ} \mathrm{C}$.

TNTx0.3 (100 mM Tris pH 7.5, $150 \mathrm{mM} \mathrm{NaCl,} \mathrm{0.3 \%} \mathrm{(v/v)} \mathrm{Triton} \mathrm{X-100)} \mathrm{(1} \mathrm{L).} \mathrm{Dissolve}$ $8.766 \mathrm{~g}$ of $\mathrm{NaCl}, 100 \mathrm{ml}$ of $1 \mathrm{M}$ Tris- $\mathrm{HCl} \mathrm{pH} 7.5$ and add $3 \mathrm{ml}$ of Triton $\mathrm{X}-100$ and fill up with deionized $\mathrm{H}_{2} \mathrm{O}$ to $1 \mathrm{~L}$.

4-lodophenylboronic acid (4-IPBA; $20 \mathrm{mg} / \mathrm{ml} ; 1000 \mathrm{X}$ stock). Dissolve 4-lodophenylboronic acid at $20 \mathrm{mg} / \mathrm{ml}$ in N-N-Dimethylformamide and store in aliquots at -20 ${ }^{\circ} \mathrm{C}$. Use at 1:1,000.

Buffered glycerol storage medium (50-80\% Glycerol (v/v), 1X PBS) (100 ml). Combine $10 \mathrm{ml}$ of $10 X$ PBS with $50-80 \mathrm{ml}$ of glycerol and fill up to $100 \mathrm{ml}$ with deionized $\mathrm{H}_{2} \mathrm{O}$. Seal the plate with an adhesive PCR plate seal to avoid spillage and evaporation.

DABCO anti-fade glycerol storage medium (50-80\% Glycerol (v/v), $20 \mathrm{mM}$ Tris- $\mathrm{HCl}$ pH $8.5,0.05 \%(w / v)$ sodium azide, $2.5 \%(w / v)$ DABCO) $(100 \mathrm{ml})$. Combine $50-80 \mathrm{ml}$ of

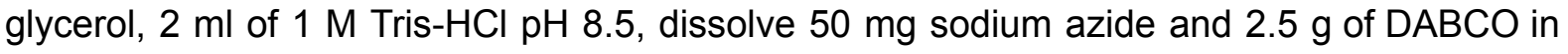
deionized $\mathrm{H}_{2} \mathrm{O}$ and fill up to $100 \mathrm{ml}$ with deionized $\mathrm{H}_{2} \mathrm{O}$. Store at $-20{ }^{\circ} \mathrm{C}$ and use working solutions at $4{ }^{\circ} \mathrm{C}$ protected from light. Seal the plate with an adhesive PCR plate seal to avoid spillage and evaporation. Sodium azide is highly toxic! Prevent contact with skin! 


\section{Supplemental protocol: Riboprobe synthesis}

This protocol describes the steps for hapten-conjugated riboprobe synthesis. Targeting $\sim 1 \mathrm{~kb}$ for riboprobe length is a good starting point, but even riboprobes of $\sim 2 \mathrm{~kb}$ against smedwi-1 work equally well. Since diffusion is not a problem with dissociated cells, riboprobe fragmentation is generally not required. Digoxigenin-labeled riboprobes give clean and robust signal and are optimal for single RNA FISH experiments. For dual RNA FISH both digoxigenin- and fluorescein-labeled riboprobes can be used. For triple FISH, an additional DNP-labeled riboprobe can be included, but its corresponding detection antibody is generally more expensive. Biotin-labeled riboprobes have been used in planarian WISH (Pearson et al. 2009), but are not popular due to endogenous biotin being present in some planarian tissues and we have not tested them. Integrity of the synthesized riboprobes can be visualized using denaturing agarose gel electrophoresis such as standard MOPS/formaldehyde (Rio 2015), Bis-Tris/PIPES/glyoxal (Burnett 1997) or TAE/formamide gel electrophoresis (Masek et al. 2005), of which the latter is the most convenient and least toxic approach. Depending on the RNA polymerase, anti-sense (T7) or sense/control riboprobes (T3) can be synthesized from the same DNA template.

\section{Reagents and equipment for riboprobe synthesis \& purification}

- 1X TAE electrophoresis buffer (40 mM Tris, $20 \mathrm{mM}$ acetate, $1 \mathrm{mM} \mathrm{Na}{ }_{2}$ EDTA, pH 7.6).

- 6X gel loading buffer (15\% (w/v) Ficoll-400, 60 mM Tris-HCl pH 7.4, 60 mM $\mathrm{Na}_{2}$ EDTA, $0.6 \%$ (w/v) Orange $\mathrm{G}$ ).

- $75 \%(\mathrm{v} / \mathrm{v})$ ethanol in deionized $\mathrm{H}_{2} \mathrm{O}$.

- 10X transcription buffer (400 mM Tris- $\mathrm{HCl} \mathrm{pH} 8.0,100 \mathrm{mM} \mathrm{MgCl} 2,100 \mathrm{mM}$ DTT, 20 $\mathrm{mM}$ spermidine). Store at $-20^{\circ} \mathrm{C}$.

- 10X DIG labeling mix (Roche, Cat. No.: 11277073910). Store at $-20{ }^{\circ} \mathrm{C}$.

- 10X Fluorescein labeling mix (Roche, Cat. No.: 11685619910). Store at $-20^{\circ} \mathrm{C}$.

- 10X DNP labeling mix (3.5 mM DNP-11-UTP, 6.5 mM UTP, 10 mM of ATP, GTP, CTP each). Store at $-20^{\circ} \mathrm{C}$.

- Absolute ethanol (MW: 46.07, CAS: 64-17-5) (any supplier).

- Ammonium acetate solution (7.5 M; MW: 77.08, CAS: 631-61-8) (Sigma, Cat. No.: A2706).

- DNase I (RNase-free, 2 U/ul) (New England Biolabs, Cat. No.: M0303).

- DNP-11-UTP (PerkinElmer, Cat. No.: NEL555001).

- NTP bundle (100 mM ATP, CTP, GTP, UTP) (Jena Bioscience, Cat. No.: NU-1014L). Store at $-20^{\circ} \mathrm{C}$.

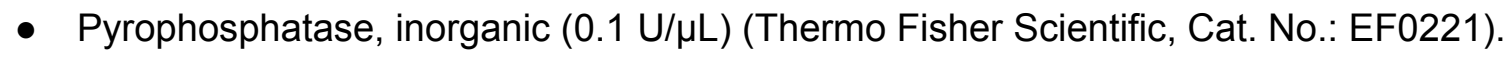

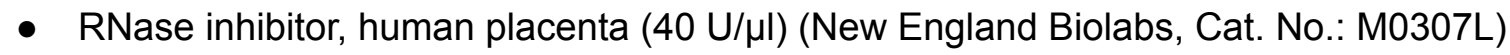

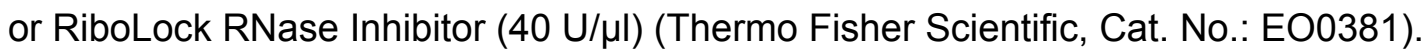

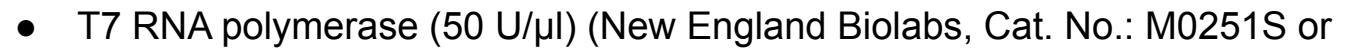
home-made).

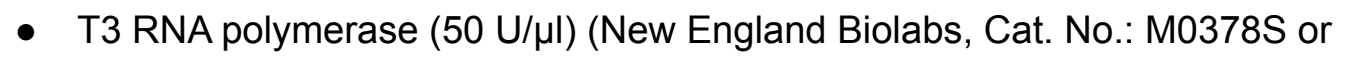
home-made).

- Optional: DNA LoBind Tubes (Eppendorf, Cat. No.: 0030108051). 


\section{Riboprobe synthesis}

1. In a $1.5 \mathrm{ml}$ tube, assemble the in vitro transcription reaction at RT to prevent spermidine precipitation. Mix the reaction carefully by pipetting up and down.

\begin{tabular}{|l|c|}
\hline Component & $\boldsymbol{\mu L}$ for $\mathbf{1}$ reaction \\
\hline deionized $\mathrm{H}_{2} \mathrm{O}$ & to $20 \mu \mathrm{l}$ \\
\hline 10X transcription buffer & 2.0 \\
\hline 10X RNA Labeling mix (DIG, Fluorescein or DNP) & 2.0 \\
\hline RNAse inhibitor $(40 \mathrm{U} / \mu \mathrm{l})$ & 0.5 \\
\hline T7 (anti-sense) or T3 $($ sense) RNA polymerase $(50 \mathrm{U} / \mu \mathrm{l})$ & 2.0 \\
\hline Inorganic Pyrophosphatase $(0.1 \mathrm{U} / \mu \mathrm{l})$ & 0.3 \\
\hline Template DNA $(\sim 0.5-1 \mu \mathrm{g})$ & variable \\
\hline TOTAL & $\mathbf{2 0}$ \\
\hline
\end{tabular}

2. Incubate the reaction $4 \mathrm{~h}$ or overnight at $37^{\circ} \mathrm{C}$.

3. To remove the template DNA at the end of riboprobe synthesis, add 1-2 units of DNase I to the reaction and mix well by pipetting.

4. Incubate for $45 \mathrm{~min}$ at $37^{\circ} \mathrm{C}$.

5. Proceed with "Riboprobe purification by ammonium acetate - ethanol precipitation".

\section{Riboprobe purification by ammonium acetate - ethanol precipitation}

1. To precipitate the riboprobe, add 0.5 volumes of $7.5 \mathrm{M}$ ammonium acetate, followed by 2.5 volumes of ice-cold absolute ethanol to the in vitro transcription reaction (Note 1). Mix by vortexing and put at $-80^{\circ} \mathrm{C}$ for at least $30 \mathrm{~min}$.

2. Spin at max velocity for $30 \mathrm{~min}$ at $4^{\circ} \mathrm{C}$. Completely aspirate the supernatant.

3. Wash the pellet extensively with $1 \mathrm{ml}$ of $75 \%$ ethanol. Vortex to dislodge the pellet.

4. Centrifuge at $12,000-16,000 \times g$ for $5 \mathrm{~min}$ at $4{ }^{\circ} \mathrm{C}$ and completely aspirate the supernatant.

5. Repeat the $75 \%$ ethanol wash and centrifugation step.

6. Resuspend the riboprobe in $100 \mu \mathrm{l}$ of formamide. (Note 2)

7. To analyze the integrity of the riboprobe, prepare a $0.8 \%(\mathrm{w} / \mathrm{v})$ agarose TAE gel.

8. Combine $4 \mu \mathrm{l}$ of formamide, $1 \mu \mathrm{l}$ of $6 \mathrm{X}$ gel loading buffer, $1 \mu \mathrm{l}$ of purified riboprobe. Mix well by vortexing or pipetting.

9. Load and electrophorese the sample(s) with an appropriate DNA marker at 5-10 $\mathrm{V} / \mathrm{cm}$ in TAE electrophoresis buffer. The single-stranded riboprobe runs faster than the DNA template (appears $\sim 1 / 2$ the size). Optionally, measure riboprobe concentration spectrophotometrically (e.g. NanoDrop).

10. Store riboprobes at $-80{ }^{\circ} \mathrm{C}$ for best long-term storage. Use riboprobes at dilutions of 1:2,000-1:4,000.

\section{Supplemental protocol: Fluorophore-conjugated tyramides}

Tyramide signal amplification, also known as catalyzed reporter deposition (CARD), is a highly sensitive method enabling the detection of low-abundance targets in fluorescent 
applications (e.g. FISH) (Hopman, Ramaekers, and Speel 1998). In the presence of $\mathrm{H}_{2} \mathrm{O}_{2}$ it involves the peroxidase-catalyzed covalent deposition of highly reactive fluorescently labeled tyramide radicals onto tyrosines surrounding the enzyme. By sequential development of tyramides coupled to spectrally different fluorophores and intermittent peroxidase inactivation, multi-color staining can be achieved. In addition to the classical fluorophores, such as AMCA (aminomethylcoumarin acetate), fluorescein, rhodamine, as well as cyanine dyes (Cy2, Сy3 and Cy5), a range of superior fluorophores have become affordable. These include e.g. the palette of sulfonated Alexa Fluor dyes (Berlier et al. 2003; Panchuk-Voloshina et al. 1999). Alexa Fluor dyes are largely $\mathrm{pH}$ insensitive, brighter and more photostable derivatives of classical dye backbones. They show reduced "dye stacking" which can lead to self-quenching and in turn decreases signal at higher labeling density. Sulfonation adds negative charges and makes the tyramides also highly water soluble and prevents trapping of the fluorophores in lipid-rich structures (Hughes, Rawle, and Boxer 2014). In our hands, the classical fluorophores can be used interchangeably with their respective dye backbone derivatives (e.g. fluorescein and Alexa 488). Depending on the final fluorophore-tyramide concentration, $1 \mathrm{mg}$ of dye succinimidyl ester (or NHS ester) is sufficient for at least 1-2 liters of tyramide development buffer. There are a range of vendors advertising their own proprietary dyes claiming improved properties (brightness, photostability, water solubility), including but not limited to iFluor (AAT Bioquest), CF Dyes (Biotium), DyLight (Thermo Fisher Scientific), ATTO dyes (ATTO-TEC), MB dyes (Fluoroprobes). In our hands, tyramides prepared from NHS esters of Alexa Fluor (or other sulfonated analogues) are compatible with planarian cells and tissues. When in doubt, the compatibility and retention with planarian cells should be tested for new types of fluorophores. Iterative TSA amplification, e.g. depositing DNP-conjugated tyramide, which can then be detected with peroxidase-conjugated anti-DNP antibody and developed with a fluorophore-conjugated tyramide, has been described elsewhere (King and Newmark 2013). For spectral properties of the fluorophores we refer to the respective manufacturers datasheet.

\section{Reagents for fluorophore-conjugated tyramide synthesis}

- Tyramine hydrochloride (MW: 173.64, CAS: 60-19-5) (Sigma, Cat. No.: T-2879)

- N,N-Dimethylformamide (DMF), anhydrous, 99.8\%, (MW: 73.09, CAS: 68-12-2) (Sigma, Cat. No.: 227056-100ML)

- Triethylamine (TEA) (MW: 101.19, CAS: 121-44-8) (Sigma, Cat. No.: 90337-5ML or 90335-100ML)

- Absolute ethanol (MW: 46.07, CAS: 64-17-5) (any supplier)

- AMCA NHS ester (MW: 330) (Thermo Fisher Scientific, Cat. No.: 33005)

- 5/6-Carboxyfluorescein NHS ester, mixed isomer (MW: 473.4) (Thermo Fisher Scientific, Cat. No.: C1311 or 46410)

- 5/6-carboxy-tetramethyl-rhodamine NHS ester (TAMRA), mixed isomer (MW: 527.52) (Thermo Fisher Scientific, Cat. No.: 46406)

- CF-Dye 405S NHS ester (MW: 1,169) (Biotium, Cat. No.: 92110)

- Cyanine 3 NHS ester (MW: 718.87) (Fluoroprobes, Cat. No.: 1301-1)

- Cyanine 5 NHS ester (MW: 739.86) (Fluoroprobes, Cat. No.: 1321-1)

- Sulfo-Cyanine 3 NHS ester (MW: 751.91) (Lumiprobe, Cat. No.: 11320)

- Sulfo-Cyanine 5 NHS ester (MW: 777.95) (Lumiprobe, Cat. No.: 13320) 
- AZDye 488 NHS ester (MW: 631.54) (Fluoroprobes, Cat. No.: 1013-1)

- AZDye 555 NHS ester (MW: 944.07) (Fluoroprobes, Cat. No.: 1166-1)

- AZDye 568 NHS ester (MW: 791.80) (Fluoroprobes, Cat. No.: 1081-1)

- AZDye 594 NHS ester (MW: 819.85) (Fluoroprobes, Cat. No.: 1101-1)

- AZDye 647 NHS ester (MW: 1,273.68) (Fluoroprobes, Cat. No.: 1121-1)

\section{Coupling reaction for generating fluorophore-conjugated tyramides}

1. To prepare the DMF-TEA coupling buffer add $100 \mu$ l triethylamine (TEA) to $9.90 \mathrm{ml}$ $\mathrm{N}, \mathrm{N}$-dimethylformamide (DMF) and mix well.

2. To prepare the $10 \mathrm{mg} / \mathrm{ml}$ tyramine $\mathrm{HCl}$ stock solution in DMF-TEA coupling buffer, add $100 \mathrm{mg}$ tyramine- $\mathrm{HCl}$ to $10 \mathrm{ml}$ of DMF-TEA coupling buffer. Mix well until all the tyramine- $\mathrm{HCl}$ is dissolved.

3. Immediately before the coupling reaction, dissolve the dry fluorophore NHS ester completely in DMF at a concentration of $10 \mathrm{mg} / \mathrm{ml}$ by vortexing and collecting drops by brief centrifugation in a table-top centrifuge. (Note 3 )

4. Add a 1.1 molar excess of the tyramine-HCl stock in DMF-TEA to the respective fluorophore NHS ester dissolved in DMF. Mix well by vortexing and collect by brief centrifugation. (See Table 1 for exemplary conjugations reactions).

5. Incubate the conjugation reaction protected from light at RT for at least 2 hours.

Extended incubations in the dark are also not problematic and will ensure the coupling reaction goes to completion and the hydrolysis of any unreacted NHS ester.

6. Dilute the fluorophore-conjugated tyramide by adding absolute ethanol for a final concentration of $1 \mathrm{mg} / \mathrm{mL}$ and store in the dark at $-20^{\circ} \mathrm{C}$. (Note 4)

\begin{tabular}{|c|c|c|c|c|c|}
\hline Dye ester & MW & mg & DMF ( $\mu \mathrm{l})$ & $\begin{array}{c}1.1 \text { molar excess tyramine } \mathrm{HCl} \\
\text { in DMF-TEA }(\mu \mathrm{l})\end{array}$ & EtOH to $1 \mathrm{mg} / \mathrm{ml}(\mu \mathrm{l})$ \\
\hline CF-Dye 405S & 1169 & $1.169^{*}$ & 100 & 19.14 & 1049.86 \\
\hline AZDye 488 & 632 & 1 & 100 & 25.03 & $874.97^{* *}$ \\
\hline Sulfo-Cy3 & 736 & 1 & 100 & 21.49 & 878.51 \\
\hline AZDye 568 & 792 & 1 & 100 & 24.17 & 875.83 \\
\hline AZDye 594 & 804 & 1 & 100 & 23.81 & 876.19 \\
\hline AZDye 647 & 1250 & 1 & 100 & 12.65 & 887.35 \\
\hline
\end{tabular}




\section{Main Protocol: Fluorescent in situ hybridization and immunocytochemistry}

The full staining protocol takes roughly 4-6 days when developing all three channels using FISH riboprobes or with phospho-H3 and/or BrdU ICC. The time estimates are for manually staining 1 or 2 full 96 -well plates, which can be conveniently handled without automated liquid handling. The protocols are organized in a modular fashion and require roughly a day per module and can be linked together by overnight incubation steps. Cells should be covered by liquid at all times and not be allowed to dry for more than a few seconds. Most of the steps use generous volumes to prevent evaporation. Costly antibody- or tyramide development solutions can likely be scaled down further, but should be tested empirically.

\section{Preparing macerated worms}

This protocol module contains all the steps required for dissociating planarians into a single cell suspension. The macerates should be directly used for downstream processing (plating, fixation etc.).

1. Before you begin, cool down the fixed-angle and swing-out plate centrifuges to $4{ }^{\circ} \mathrm{C}$.

2. Transfer worms into a $2 \mathrm{ml}$ tube, remove all liquid and add ice-cold maceration solution to the animals. A good starting point is generating $\sim 500,000 \mathrm{cells} / \mathrm{ml}$ of maceration which corresponds to a $\sim 5 \mathrm{~mm}$ worm of $S$. mediterranea (CIW4 strain) dissociated in $1 \mathrm{ml}$ of maceration solution. (Note 5, 6, 7)

3. Let the tubes incubate for $15 \mathrm{~min}$ on ice in the cold room.

4. Afterwards, place the tube(s) on a rotator in the cold room and incubate them for an additional $15-30 \mathrm{~min}$.

5. Most of the tissue should be dissociated by now. Carefully pipette up and down using a p1000 to dissociate remaining tissue clumps or when there are dark "clouds" in the cell suspension. Pharynx tissue takes the longest to dissociate.

6. If necessary, dilute the cell suspension with ice-cold maceration solution.

7. Briefly collect the cells by spinning for $10 \mathrm{~s} / 500 \mathrm{xg} / 4{ }^{\circ} \mathrm{C}$ in a fixed-angle centrifuge, put the cells on ice and proceed with "Preparing the plate(s) and fixation of cells".

\section{Preparing macerated worms for storage}

Use this option if the samples have to be stored frozen and processed at a later time point. For preparing worms for storage, the animals are initially dissociated and frozen at $-80^{\circ} \mathrm{C}$ in a smaller volume containing a higher glycerol concentration as cryo-protectant. After thawing, the glycerol is diluted with a glycerol-free maceration dilution solution to yield the desired cell densities. The diluted cell suspension is equivalent to freshly macerated worms (see above).

1. Transfer worms into a $2 \mathrm{ml}$ tube, remove all liquid and add ice-cold maceration solution at 1/10th of the volume of final desired maceration solution volume (e.g. 100 $\mu \mathrm{l}$ for $1 \mathrm{ml}$ final volume). (Note $5,6,7$ ) 
2. Let the tubes incubate for $15 \mathrm{~min}$ on ice in the cold room.

3. Afterwards, place the tube(s) on a rotator in the cold room and incubate them for an additional 15-30 min.

4. Most of the tissue should be dissociated by now. Carefully pipette up and down using a p1000 to dissociate remaining tissue clumps or when there are dark "clouds" in the cell suspension. Pharynx tissue takes the longest to dissociate.

5. Briefly collect cells by centrifugation for $10 \mathrm{~s} / 500 \times \mathrm{g} / 4{ }^{\circ} \mathrm{C}$ in a fixed-angle tabletop centrifuge and then add 0.6 volumes of glycerol to the cells and put on a rotator in the cold room for additional $15 \mathrm{~min}$ (e.g. $60 \mu \mathrm{l}$ for $1 \mathrm{ml}$ final volume). (Note 8)

6. Briefly collect cells by centrifugation for $10 \mathrm{~s} / 500 \times \mathrm{g} / 4{ }^{\circ} \mathrm{C}$ in a fixed-angle tabletop centrifuge. Snap-freeze in liquid nitrogen and store at $-80{ }^{\circ} \mathrm{C}$ until needed.

7. Before starting the experiment, place the frozen aliquots on ice and add glycerol-free maceration dilution solution to the final volume (e.g. $840 \mu \mathrm{l}$ for $1 \mathrm{ml}$ final volume).

8. Place tube(s) on a rotator in the cold room for $10 \mathrm{~min} / 4{ }^{\circ} \mathrm{C}$.

9. Briefly collect the cells by centrifugation for $10 \mathrm{~s} / 500 \times \mathrm{g} / 4{ }^{\circ} \mathrm{C}$ in a fixed-angle tabletop centrifuge, put the cells on wet ice and proceed with "Preparing the plate(s) and fixation of cells".

\section{Preparing the plate(s) and fixation of cells}

This protocol module contains all the steps required for fixing the cells onto the bottom of a 96 well plate. Due to spatial constraints, all steps in 384-well plates are performed in $\sim 25 \%$ of the volume and require automated liquid handling. We refer to the respective manufacturer's documentation for setting up automated liquid handling solutions.

1. Preparing the following solutions before starting will help reducing delays during processing of the cells:

a. $15 \%$ PFA/1X PBS $(45 \mu \mathrm{l} /$ well $)$

b. $4 \%$ PFA/1X PBS $(100 \mu \mathrm{l} /$ well $)$

2. Distribute $120 \mu \mathrm{l}$ of cell suspension from macerated worms into each of the wells of a 96-well plate (see "Preparing macerated worms / Preparing macerated worms for storage").

3. Gently pellet cells for $5 \mathrm{~min} / 2,000 \times \mathrm{g} / 4^{\circ} \mathrm{C}$ in a swing-out plate centrifuge. For a single plate experiment, fill up a counterbalance plate accordingly with $\mathrm{H}_{2} \mathrm{O}$. (Note 9)

4. Under a fume hood, gently add $45 \mu \mathrm{l}$ of $15 \%$ PFA per well to a final concentration of $4 \%$ PFA and incubate the cells for $15-20$ min at RT. (Note 10)

5. Carefully remove $4 \%$ PFA/maceration solution and slowly add $200 \mu \mathrm{l}$ of $1 \mathrm{X}$ PBS.

6. Repeat the $1 X$ PBS wash by carefully removing $1 X$ PBS and slowly adding fresh 200 $\mu$ of $1 X$ PBS. (Note 11)

7. Remove $1 \mathrm{X}$ PBS and post-fix the cells by adding $100 \mu \mathrm{l}$ of $4 \%$ PFA in $1 \mathrm{X}$ PBS for 15-20 min at RT.

8. Remove fixative and incubate with $200 \mu \mathrm{l}$ of quenching buffer for $15 \mathrm{~min}$ at RT. (Note 12,13)

9. Remove quenching buffer and rinse once with $200 \mu$ I PBSTx 0.1 followed by $1 \mathrm{x}$ wash with $200 \mu \mathrm{l}$ of PBSTx0.1 for 5 min.

10. Proceed with "Probe hybridization \& washing". 


\section{Probe hybridization \& washing}

This protocol module contains all the steps required for preparing the plates for riboprobe hybridization and subsequent washing steps. Optionally, the experiment can be paused by storing the plates at $-20^{\circ} \mathrm{C}$ in PreHyb before the addition of the riboprobes (Note 14).

1. Bring sufficient WashHyb $(25 \mu \mathrm{l} /$ well $)$ and PreHyb $(100 \mu \mathrm{l} /$ well $)$ from $-20{ }^{\circ} \mathrm{C}$ to $\mathrm{RT}$.

2. Remove PBSTX0.1 and incubate the cells with $50 \mu \mathrm{l}$ of equal parts PBSTx0.1/WashHyb for 5 min at RT.

3. To block the cells, incubate with $100 \mu$ l of PreHyb for $45-60$ min at $56-58{ }^{\circ} \mathrm{C}$ in an incubation oven.

4. In the meantime, bring $\mathrm{Hyb}\left(\mathrm{or} \mathrm{Hyb}+\right.$ ) to $56-58^{\circ} \mathrm{C}$ and start preparing the riboprobes.

5. Briefly denature the riboprobes $5 \mathrm{~min}$ at $70{ }^{\circ} \mathrm{C}$ and immediately dilute DIG/fluorescein/DNP riboprobes in $\mathrm{Hyb}$ or $\mathrm{Hyb}+$ at 1:2,000 to 1:4,000 depending on the riboprobe. (Note 15)

6. Remove PreHyb and incubate with $150-200 \mu \mathrm{Hyb}$ (or Hyb+), including riboprobes for $12-16 \mathrm{~h}$ at $56-58^{\circ} \mathrm{C}$ in an incubation oven, preferable with shaking. To prevent evaporation, fill empty wells with water and seal the plate using adhesive PCR plate seals.

7. On the next day, before you begin, pre-warm the following solutions at $56-58^{\circ} \mathrm{C}$ :
a. WashHyb (100 $\mu \mathrm{l} / \mathrm{well})$
b. $2 X S S C /$ WashHyb $(100 \mu \mathrm{l} /$ well $)$
c. $2 X$ SSCTX0.1 (400 $\mu \mathrm{l} / \mathrm{well})$
d. $0.2 \times$ SSCTX0.1 (400 $\mu \mathrm{l} /$ well $)$

8. Remove $\mathrm{Hyb}(\mathrm{or} \mathrm{Hyb+)}$ and wash $1 \mathrm{x}$ with $100 \mu$ of pre-warmed WashHyb for $15 \mathrm{~min}$ at $56-58{ }^{\circ} \mathrm{C}$. (Note 16)

9. Remove the solution and wash $1 \mathrm{x}$ with $100 \mu$ of pre-warmed $1: 12 \mathrm{XSSC}$ WashHyb for 15 min at $56-58^{\circ} \mathrm{C}$.

10. Remove the solution and wash $2 x$ with $200 \mu$ of pre-warmed 2 X SSCTx 0.1 for 10 $\min$ at $56-58^{\circ} \mathrm{C}$.

11. Remove the solution and wash $2 x$ with $200 \mu$ l of pre-warmed $0.2 \times$ SSCTx 0.1 for 10 $\min$ at $56-58^{\circ} \mathrm{C}$.

12. Bring the plate(s) to RT. Remove the solution and rinse once with $200 \mu \mathrm{PBST} \times 0.1$ followed by $1 \mathrm{x}$ wash with $200 \mu \mathrm{l}$ PBSTx0.1 for $10 \mathrm{~min}$.

13. Proceed with "Tyramide signal amplification - DIG-/FL-/DNP-probes".

\section{Tyramide signal amplification - Digoxigenin riboprobe (DIG-probe)}

This protocol module is designed for the detection of digoxigenin-conjugated riboprobes (DIG-probe). Digoxigenin probes are the workhorse of many ISH assays (colorimetric/fluorescent) and this detection system typically generates very specific staining with little background in our hands (i.e. speckles). DIG-probes are recommended for weak targets, which should be developed first. 
1. Remove PBSTx 0.1 and block with $50 \mu$ l of $5 \%(v / v)$ horse serum (1:20 dilution) + $0.5 \%$ (v/v) Roche Western Blocking Reagent (RWBR) (1:20 dilution) in PBSTx0.1 for 30-60 min at RT.

2. Remove solution and add $100 \mu$ of PBSTx0.1, containing anti-DIG-POD $(1: 4,000)+$ $1 \%(\mathrm{v} / \mathrm{v})$ horse serum (1:100 dilution) $+0.1 \%(\mathrm{v} / \mathrm{v})$ RWBR and incubate at 3-4 h RT. (Note 17)

3. Remove solution and rinse once with $200 \mu \mathrm{l}$ of PBSTx 0.1 and wash $3 \times 20$ min with $200 \mu$ l of PBSTx0.1.

4. Remove PBSTx0.1 and incubate with $100 \mu$ of TSA (or TSA+) buffer to develop the tyramide for $15-30$ min at RT in containing:

a. $\quad 0.5-1 \mu \mathrm{g} / \mathrm{ml}$ fluorophore-conjugated tyramide $(1: 2,000-1,000$ of $1 \mathrm{mg} / \mathrm{ml} \mathrm{stock})$ (Note 18)

b. $0.006 \%\left(1: 5,000\right.$ of $30 \% \mathrm{H}_{2} \mathrm{O}_{2}$ stock $)$

c. $20 \mu \mathrm{g} / \mathrm{ml}$ of 4 -lodophenylboronic acid $(1: 1,000$ of $20 \mathrm{mg} / \mathrm{ml}$ stock)

5. Remove solution and rinse once with $200 \mu \mathrm{l}$ of PBSTx0.1 and wash $1 \times 10$ min with $200 \mu$ l of PBSTx0.1.

6. Incubate with $100 \mu \mathrm{l}$ of $25 \mathrm{mM}$ sodium azide in PBSTx 0.1 for $15 \mathrm{~min}$ at RT or overnight at $4{ }^{\circ} \mathrm{C}$ (Note 19).

7. Remove the solution and rinse $2 x$ with $200 \mu$ of PBST $x 0.1$ and wash $3 \times 10$ min with $200 \mu$ of PBSTx0.1.

\section{Tyramide signal amplification - Fluorescein riboprobe (FL-probe)}

This protocol module is designed for the detection of fluorescein-conjugated riboprobes (FL-probes). As fluorescein is a fluorophore by itself, the riboprobe is generally developed using a spectrally identical fluorescein- or AF488-conjugated tyramide. Please note the slightly different blocking conditions for this assay (Note 20).

1. Remove PBSTx 0.1 and block with $50 \mu$ of $5 \%(v / v)$ horse serum ( $1: 20$ dilution $)+1 \%$ $(\mathrm{v} / \mathrm{v})$ RWBR (1:20 dilution) $+0.2 \%$ (w/v) porcine gelatin in PBSTx0.1 for 30-60 min at RT.

2. Remove solution and incubate with $100 \mu \mathrm{l}$ of PBSTx0.1 containing anti-fluorescein-POD $(1: 2,000)$ in $5 \%(v / v)$ horse serum, 1\% (v/v) RWBR, $0.04 \%$ $(\mathrm{w} / \mathrm{v})$ porcine gelatin and incubate at 3-4 h RT. (Note 17)

3. Remove solution and rinse once with $200 \mu \mathrm{l}$ of PBSTx0.1 and wash $3 \times 20$ min with $200 \mu$ l of PBST 0.1.

4. Remove PBSTx0.1 and incubate with $100 \mu$ of TSA/TSA+ buffer to develop the tyramide for 15-30 min at RT in containing:

a. $0.5-1 \mu \mathrm{g} / \mathrm{ml}$ fluorophore-conjugated tyramide $(1: 2,000-1,000 \mathrm{of} 1 \mathrm{mg} / \mathrm{ml}$ stock) (Note 18)

b. $0.006 \%\left(1: 5,000\right.$ of $30 \% \mathrm{H}_{2} \mathrm{O}_{2}$ stock $)$

c. $20 \mu \mathrm{g} / \mathrm{ml}$ of 4 -lodophenylboronic acid $(1: 1,000$ of $20 \mathrm{mg} / \mathrm{ml}$ stock)

5. Remove solution and rinse once with $200 \mu \mathrm{l}$ of PBSTx0.1 and wash $1 \times 10$ min with $200 \mu$ PBST 0.1 .

6. Incubate with $100 \mu \mathrm{l}$ of $25 \mathrm{mM}$ sodium azide in PBSTx 0.1 for $15 \mathrm{~min}$ at RT or overnight at $4{ }^{\circ} \mathrm{C}$ (Note 19). 
7. Remove the solution and rinse $2 x$ with $200 \mu$ l of PBSTx 0.1 and wash $3 \times 10$ min with $200 \mu$ l of PBSTx0.1.

\section{Tyramide signal amplification - Dinitrophenyl riboprobe (DNP-probe)}

This protocol module is designed for the detection of dinitrophenyl-conjugated riboprobes (DNP-probes). While it is compatible with the plate format, the commonly used antibody (PerkinElmer, Cat. No.: FP1128) makes this riboprobe/antibody combination rather expensive in high-content assays (Note 21).

1. Remove PBSTx 0.1 and block with $50 \mu$ of $5 \%(v / v)$ horse serum $+0.5 \%(v / v)$ RWBR in TBSTx0.3 for 30-60 min at RT.

2. Remove TBST $x 0.3$ and incubate with $50 \mu$ of TBST 0.3 containing anti-DNP-POD $(1: 300)$ in $1 \%(w / v)$ horse serum, $0.1 \%(w / v)$ RWBR and incubate at 3-4 h RT. (Note 17)

3. Remove solution and rinse once with $200 \mu$ of TBST 0.3 and wash $3 \times 20$ min with $200 \mu$ l of TBSTx0.3.

4. Remove TBSTX0.3 and incubate with $100 \mu$ of TSA/TSA+ buffer to develop the tyramide for 15-30 min at RT in containing:

a. $\quad 0.5-1 \mu \mathrm{g} / \mathrm{ml}$ fluorophore-conjugated tyramide $(1: 2,000-1,000$ of $1 \mathrm{mg} / \mathrm{ml} \mathrm{stock})$ (Note 18)

b. $0.006 \%\left(1: 5,000\right.$ of $30 \% \mathrm{H}_{2} \mathrm{O}_{2}$ stock $)$

c. $20 \mu \mathrm{g} / \mathrm{ml}$ of 4 -lodophenylboronic acid $(1: 1,000$ of $20 \mathrm{mg} / \mathrm{ml} \mathrm{stock})$

5. Remove solution and rinse once with $200 \mu$ of TBSTx 0.3 and wash $1 \times 10$ min with $200 \mu$ of TBSTx0.3.

6. Incubate with $100 \mu \mathrm{l}$ of $25 \mathrm{mM}$ sodium azide in PBSTx0.1 for $15 \mathrm{~min}$ at RT or overnight at $4{ }^{\circ} \mathrm{C}$ (Note 19).

7. Remove the solution and rinse $2 x$ with $200 \mu \mathrm{l}$ of PBSTx0.1 and wash $3 \times 10$ min with $200 \mu$ l of PBSTx0.1.

\section{ICC phospho-histone H3 staining of M-phase}

This protocol module uses primary antibodies against phospho-histone $\mathrm{H} 3$ as a marker for cells in metaphase (M-phase). Detection is accomplished using fluorophore conjugated secondary antibodies, preferably Alexa Fluor 647-conjugated, although other detection schemes are possible. This protocol also serves as a basis for ICC using a range of other antibodies.

1. Remove PBSTx0.1 and block with $50 \mu$ of $5 \%(v / v)$ goat serum, $0.5 \%(v / v)$ RWBR in PBSTx 0.1 or TBST 0.1 for 30 min at RT. (Note 22, 23)

2. Remove blocking solution and incubate with $50 \mu$ lof primary rabbit anti-phospho $\mathrm{H} 3$ antibody $(1: 1,000)$ in $1 \%(\mathrm{v} / \mathrm{v})$ goat serum, $0.1 \%(\mathrm{v} / \mathrm{v})$ RWBR in $50 \mu \mathrm{l}$ of PBSTx0.1 or TBSTx0.1. Incubate at $4{ }^{\circ} \mathrm{C}$ overnight or $3-4 \mathrm{~h}$ at RT. (Note 24)

3. Remove solution and rinse once with $200 \mu \mathrm{l}$ of PBSTx0.1 and wash $3 \times 10$ min with $200 \mu$ l of PBSTx0.1. 
4. Replace PBSTx0.1 with $50 \mu \mathrm{l}$ of $1 \%(\mathrm{v} / \mathrm{v})$ goat serum, $0.1 \%(\mathrm{v} / \mathrm{v}) \mathrm{RWBR}$ in PBSTx0.1, containing goat anti-rabbit Alexa-647 secondary antibody $(1: 1,000)$ for 3-4 $\mathrm{h}$ at RT. (Note 24)

5. Remove solution and rinse once with $200 \mu \mathrm{l}$ of PBSTx0.1 and wash $3 \times 15$ min with $200 \mu$ of PBSTx0.1.

\section{ICC/TSA phospho-histone H3 staining of M-phase}

This protocol module is a more sensitive modification of the ICC protocol for the detection of phospho-histone $\mathrm{H} 3$ and is required in combination with BrdU detection in the same experiment (see "Detection of incorporated BrdU during DNA synthesis"). The phospho-histone $\mathrm{H} 3$ positive nuclei are covalently labeled using tyramide signal amplification as the BrdU antigen retrieval would otherwise destroy non-covalent antibody staining.

1. Remove PBSTx0.1 and block with $50 \mu \mathrm{l}$ of $5 \%(\mathrm{v} / \mathrm{v})$ goat serum, $0.5 \%(\mathrm{v} / \mathrm{v}) \mathrm{RWBR}$ in PBSTx0.1 or TBSTx0.1 for $15-30$ min at RT. (Note 22, 23)

2. Remove blocking solution and incubate with $50 \mu \mathrm{l}$ of primary rabbit anti-phospho $\mathrm{H} 3$ antibody $(1: 1,000)$ in $1 \%(\mathrm{v} / \mathrm{v})$ goat serum, $0.1 \%(\mathrm{v} / \mathrm{v})$ RWBR in $50 \mu \mathrm{IPBST} 0.1$ or TBSTx0.1. Incubate at $4{ }^{\circ} \mathrm{C}$ overnight or $3-4 \mathrm{~h}$ at RT. (Note 24)

3. Remove solution and rinse once with $200 \mu \mathrm{l}$ of PBSTx0.1 and wash $3 \times 20$ min with $200 \mu$ of PBSTX0.1.

4. Replace PBSTx0.1 with $50 \mu$ of donkey anti-rabbit-POD $(1: 1,000-1: 2,000)$ in $1 \%(\mathrm{v} / \mathrm{v})$ horse serum, $0.1 \%$ (v/v) RWBR in PBSTx0.1 for 3-4 h at RT. (Note 24)

5. Remove solution and rinse once with $200 \mu \mathrm{l}$ of PBSTx0.1 and wash $3 \times 20$ min with $200 \mu$ l of PBSTx0.1.

6. Remove PBSTx0.1 and incubate with $100 \mu$ of TSA/TSA+ buffer to develop the tyramide for 15-30 min at RT in containing:

a. $0.5-1 \mu \mathrm{g} / \mathrm{ml}$ fluorophore-conjugated tyramide $(1: 2,000-1,000$ of $1 \mathrm{mg} / \mathrm{ml} \mathrm{stock})$ (Note 18)

b. $0.006 \%\left(1: 5,000\right.$ of $30 \% \mathrm{H}_{2} \mathrm{O}_{2}$ stock $)$

c. $20 \mu \mathrm{g} / \mathrm{ml}$ of 4 -lodophenylboronic acid $(1: 1,000$ of $20 \mathrm{mg} / \mathrm{ml}$ stock)

7. Remove solution and rinse once with $200 \mu \mathrm{PBSTx} 0.1$ and wash $1 \times 10$ min with 200 $\mu \mathrm{IBBST} 0.1$.

8. Incubate with $100 \mu \mathrm{l}$ of $25 \mathrm{mM}$ sodium azide in PBSTx0.1 for $15 \mathrm{~min}$ at RT or overnight at $4{ }^{\circ} \mathrm{C}$ (Note 19).

9. Remove the solution and rinse $2 x$ with $200 \mu$ l of PBST 0.1 and wash $3 \times 10$ min with $200 \mu$ of PBSTX0.1.

\section{Detection of incorporated BrdU during DNA synthesis}

This protocol module is designed for the detection of cells that have incorporated BrdU into their nuclear DNA. It includes antigen retrieval (DNA denaturation) and the detection of the exposed BrdU using the murine Bu20a antibody and fluorophore-conjugated tyramide signal amplification. BrdU delivery strategies and BrdU pulse-chase durations are largely dependent on the biological question and have been covered in detail elsewhere (Cheng and Alvarado 2018). Existing BrdU pulse chase protocols for whole mounts should be directly adaptable to the plate format without additional modifications. 
1. Remove PBST $x 0.1$ and denature the DNA in $50-100 \mu \mathrm{l}$ of freshly prepared $2 \mathrm{~N} \mathrm{HCl}$ for 20-30 min at RT to expose the BrdU epitope. (Note 25)

2. Remove $2 \mathrm{~N} \mathrm{HCl}$ and neutralize with $200 \mu$ of $0.1 \mathrm{M}$ sodium borate buffer $(\mathrm{pH}$ 8.5) for 10 min at RT.

3. Remove $0.1 \mathrm{M}$ sodium borate buffer and wash the cells $2 \times 5$ min with $200 \mu \mathrm{l}$ of PBSTX0.1.

4. Block the cells with $50 \mu \mathrm{l}$ of $5 \%(\mathrm{v} / \mathrm{v})$ horse or goat serum, $0.5 \%(\mathrm{v} / \mathrm{v})$ RWBR in PBST 0.1 for $30-60$ min at RT.

5. Replace blocking solution with $50 \mu$ of PBSTx $0.1,1 \%(\mathrm{v} / \mathrm{v})$ horse serum, $0.1 \%(\mathrm{v} / \mathrm{v})$ RWBR containing primary antibody (e.g. mouse clone Bu20a, $2 \mu \mathrm{g} / \mathrm{ml}, 1: 1,000$ ). Incubate overnight at $4{ }^{\circ} \mathrm{C}$. (Note 24)

6. The next day, remove the solution and rinse once with $200 \mu \mathrm{l}$ PBSTx0.1 and wash $2 x$ 10 min with $200 \mu$ l of PBSTx0.1.

7. Replace PBSTx0.1 with $100 \mu$ of PBSTx0.1, $1 \%(\mathrm{v} / \mathrm{v})$ horse serum, $0.1 \%(\mathrm{v} / \mathrm{v})$ RWBR, containing secondary antibody (donkey anti-mouse POD) $(1: 1,000)$ for $3-4 \mathrm{~h}$ at RT.

8. Remove solution and rinse once with $200 \mu \mathrm{l}$ of PBSTx 0.1 and wash $3 \times 15$ min with $200 \mu$ of PBSTx0.1.

9. Remove PBSTx0.1 and incubate with $100 \mu \mathrm{l}$ of TSA (or TSA+) buffer to develop tyramide for $15-30$ min at RT in containing:

a. $\quad 0.5-1 \mu \mathrm{g} / \mathrm{ml}$ fluorophore-conjugated tyramide $(1: 2,000-1,000 \mathrm{of} 1 \mathrm{mg} / \mathrm{ml} \mathrm{stock})$ (Note 18)

b. $0.006 \%\left(1: 5,000\right.$ of $30 \% \mathrm{H}_{2} \mathrm{O}_{2}$ stock $)$

c. $20 \mu \mathrm{g} / \mathrm{ml}$ of 4-lodophenylboronic acid $(1: 1,000 \mathrm{of} 20 \mathrm{mg} / \mathrm{ml}$ stock)

10. Remove solution and rinse once with $200 \mu \mathrm{l}$ of PBSTx0.1 and wash $2 \times 10$ min with $200 \mu$ of PBSTX0.1.

11. BrdU stained plates are incompatible with DABCO-containing storage medium and should be stored in buffered glycerol storage medium or PBSTx0.1. (Note 26)

\section{Nuclear DNA staining}

This protocol module describes the staining of nuclei using dsDNA specific dyes. This is commonly done using DAPI, but spectrally similar dyes include Hoechst 33342 and Nuclear Violet $^{\mathrm{TM}}$ LCS1. Alternatively, DRAQ5 can be used for far red imaging. For consistent staining, nuclear DNA staining should be performed as a final step before imaging.

1. Remove PBSTx 0.1 and add $50 \mu$ of PBST 0.1 including DAPI $(0.1-1 \mu \mathrm{g} / \mathrm{ml} ; 1: 5,000$ $-10,000$ ) or other suitable nuclear stain and incubate for $30 \mathrm{~min}$ at RT.

2. Remove solution and rinse once with $200 \mu \mathrm{l}$ of PBSTX0.1.

3. Remove PBSTx0.1 and wash $1 \times 5$ min with $200 \mu \mathrm{l} 1 \mathrm{X}$ PBS.

4. Remove PBS and store cells in 100-200 $\mu$ of glycerol based storage medium at $4{ }^{\circ} \mathrm{C}$ (or $-20^{\circ} \mathrm{C}$ ), protected from light. 


\section{Notes}

- Note 1: Ammonium acetate is the salt of choice for ethanol precipitation of riboprobes as it tends to keep unincorporated hapten-NTPs in solution, which could lead to background staining.

- Note 2: Once dissolved in formamide, riboprobes are extremely difficult to re-precipitate again, so the pellet should be washed thoroughly (Nadin-Davis and Mezl 1982).

- Note 3: NHS-esters are prone to hydrolysis and therefore the entire content of the tube should be dissolved in anhydrous DMF and used immediately for the coupling reaction.

- Note 4: Some Fluorophore-coupled tyramides will partially precipitate upon storage at $-20{ }^{\circ} \mathrm{C}$ (e.g. Alexa Fluor 488-tyramide). Make sure to warm the tube to RT and fully resuspend the tyramide before use. Alternatively, dilute the coupling reaction in DMF instead of ethanol to the desired concentration.

- Note 5: As animal cell number does not scale linearly with animal length, we refer to the literature for cell numbers over a broad range of animal sizes (Thommen et al. 2019). For a given S. mediterranea (CIW4; 1-2 weeks starved), the number of cells $(y)$ of worm length in $\mathrm{mm}(\mathrm{x})$ can be approximated using the equation: $\mathrm{y}=15981 \mathrm{x}^{2}+$ $52774 x$ - 25382. Note that some RNAi phenotypes, especially of genes important for stem cell function will prevent the worms from growing. Compared to control worms, these will have fewer cells, therefore volumes or number of worms have to be adjusted accordingly.

- Note 6: The round bottom of $2 \mathrm{ml}$ tubes helps the liquids to mix more thoroughly. Conical $1.5 \mathrm{ml}$ tubes often lead to tissue being trapped at the bottom of the tube.

- Note 7: Worms can also be macerated using methanol containing solutions (13:3:2:2 ratio of distilled water, methanol, glacial acetic acid and glycerol (Baguñà 1976). While inclusion of methanol preserves morphology slightly better, dissociation is much slower and might require more manual pipetting, which is cumbersome when processing many samples in parallel. Furthermore, the chemical compatibility of the polystyrene plates with methanol is limited, therefore caution is advised as we have not extensively tested other maceration solutions. While maceration at room temperature is possible and dissociation is faster, we have found that some DNA degradation occurs. To ensure more consistent results and limit endogenous enzyme activity, maceration at cold temperatures is recommended.

- Note 8: Glycerol is very viscous at cold temperatures. Using a repeater pipette with Combitips makes dispensing glycerol more efficient and consistent. Note that Combitips have fixed volume increments, so volume choices are not arbitrary.

- Note 9: Do not spin the plates above 2000xg as they might crack. Changing this parameter might require adjusted centrifugation times.

- Note 10: To prevent cells from aggregating at the edges of the wells, do not move or shake the plates and keep them in a horizontal position during fixation.

- Note 11: Formaldehyde fixation is inefficient at low pH (Thavarajah et al. 2012) and cells are pre-infiltrated with fixative at this step. Take care to pipette down the wall of the well and not to disturb the cells to prevent cell loss and movement within wells. It is fine to not completely remove all of the liquid during 1X PBS washes and keep a ring of liquid around the well edges. The $1 \mathrm{X}$ PBS washes neutralize the $\mathrm{pH}$ for efficient post-fixation. 
- Note 12: A repeater pipette is safe to use from this point on and the plates can now be propped up at a $45^{\circ}$ angle for washing in a well plate stand or as a cheap alternative in a tip box lid. When possible, the plate should be rocked gently on a nutator from now on throughout the process, but it is not critical. Liquid removal speed using a vacuum pump can be tuned by attaching different tips (p10 or p200).

- Note 13: Tris and glycine quench PFA induced autofluorescence and the sodium azide inactivates endogenous peroxidases that might have survived and could generate unspecific background in TSA. Do not use any detergents up to this point.

- Note 14: Instead of proceeding with blocking and hybridization, the plates can be stored in PreHyb at $-20^{\circ} \mathrm{C}$ after addition of PreHyb. To continue staining after storage at $-20{ }^{\circ} \mathrm{C}$, bring the plate to $\mathrm{RT}$ and proceed with heating the plate up to hybridization temperature in an incubator oven.

- Note 15: For very complex riboprobe combinations and plate layouts, pre-aliquot the riboprobes in Hyb in a PCR plate and use a multi-channel pipette for transfer.

- Note 16:The repeater pipette tips can be pre-heated together with the solutions in an incubation oven to prevent volume changes when taken up heated solutions with the RT tip.

- Note 17: Optionally filter the antibody using a syringe filter (PES, $0.22 \mu \mathrm{m}$ ). Then afterwards add Roche Western Blocking Reagent.

- Note 18: Optionally filter the TSA (or TSA+) buffer with the tyramide using a syringe filter (PES, $0.22 \mu \mathrm{m}$ ) to get rid of fluorescent precipitates if that is a problem.

- Note 19: This inactivates the peroxidase to allow subsequent tyramide development for additional targets. The omission of this step can lead to unspecific tyramide deposition in the next tyramide signal amplification reaction. If no further tyramide signal amplification is required in the experiment, azide treatment can be skipped. Make sure to not have any sodium azide present when working with peroxidase-conjugated antibodies as this will inactivate the enzyme.

- Note 20: In our hands, the anti-fluorescein-POD antibody (Roche, Cat. No.:11426346910) generally requires more stringent blocking conditions and skipping the blocking step or diluting the blocking reagents often leads to a higher background. We have found that the inclusion of porcine skin gelatin in addition to RWBR improved staining. Pig-derived gelatin also improved specificity of some fluorophore conjugated secondary antibodies (e.g. ThermoFisher Scientific, Cat. No.: A-11004). The gelatin becomes quite viscous at colder temperatures, so blocking and incubation should be done at RT to maximize diffusion. Potentially, the antibody concentration could be reduced further to improve specificity, but we have not systematically tested this.

- Note 21: For routine work we use a combination of DIG- and FL-probes as the commonly used anti-DNP-POD antibody (Perkin Elmer Cat. No.: FP1128) is required at much higher concentrations. Anti-DNP POD-conjugated antibodies are only available from a few commercial vendors. SYnabs S.A. (Gosselies, Belgium) has a large selection of commercial anti-DNP antibodies which can also be ordered as POD-conjugates and might represent an alternative.

- Note 22: Buffer choice of PBSTx0.1 vs TBSTx0.1 depends on the primary antibody and should be tested, although we routinely use PBSTX0.1 for detecting phospho-histone H3 (S10/T11). We prefer PBSTX0.1 as a standard buffer because it is very cheap, but standard TBSTX0.3 used in WISH performs equally well ((King and Newmark 2013). 
- Note 23: After developing the second riboprobe, blocking can be kept short. It is still advisable to re-block after each tyramide development reaction as the TSA/TSA+ buffer has high ionic strength, which likely washes off bound blocking proteins.

- Note 24: Elongated incubations at $4{ }^{\circ} \mathrm{C}$, such as overnight or weekends for primary and/or secondary antibodies do not negatively affect staining and if at all, improve signal. If there are problems with precipitates, filter the solution (PES, $0.22 \mu \mathrm{m}$ ) before adding RWBR.

- Note 25: The BrdU antigen retrieval time should be carefully controlled. Too short treatment will not not expose the antigen optimally, whereas extended incubations will increase background and eventually hydrolyze the DNA, abolishing staining with nuclear DNA dyes. Different anti-BrdU antibodies might slightly differ in their affinity for BrdU and their performance with different antigen retrieval strategies (Ligasová et al. 2017, 2015).

- Note 26: Samples that went through the BrdU protocol are incompatible with DABCO containing storage medium and generate irreversible and unacceptable high background signal when excited at $405 \mathrm{~nm}$ measured with DAPI emission filters (BP445/45). This is specific for UV/violet light excitation in combination with $\mathrm{HCl}$ antigen retrieval as channels excited at 488,561 and $640 \mathrm{~nm}$ are not affected. Therefore, we recommend imaging and storing cells after BrdU staining in buffered glycerol without antifade. We have not tested whether n-propyl gallate as an antifade might be substituted for DABCO in experiments involving BrdU stained cells.

\section{Troubleshooting}

- Problem: The tissue composition of the macerates from the same samples changes between wells.

- Reason: Macerate not properly mixed before plating.

- Solution: Pipette carefully up and down to generate a homogeneous suspension.

- Problem: Large clumps visible on the plate.

- Reason 1: Macerate not properly mixed before plating the cells.

- Solution 1: Pipette carefully up and down to generate a homogeneous suspension.

- Reason 2: Cell seeding density too high.

- Solution 2: Dilute cells with more maceration solution or filter through yellow Celltrics filter $(50 \mu \mathrm{m})$.

- Problem: Missing cells or empty areas in wells.

- Reason 1: Too few cells plated, cells suspension too dilute.

- Solution 1: Use more worms or reduce maceration solution volume.

- Reason 2: Cells under-fixed due to low $\mathrm{pH}$ and incomplete removal of maceration solution before formaldehyde fixation.

- Solution 2: Make sure to remove the maceration solution as much as possible.

- Reason 3: Pipetting/washing conditions are too harsh.

○ Solution 3: Pipette solutions slower/more gently.

- Problem: Gradient of cell density within a well, increasing from top to bottom edge within a well. 
- Reason: Cells under-fixed due to low $\mathrm{pH}$ and incomplete removal of maceration solution before formaldehyde fixation. Cells slide downwards when the plate is propped up and accumulate at the bottom edge.

- Solution: Make sure to remove the maceration solution as much as possible.

- Problem: Declining signal or weaker signal after tyramide amplification in following experiments.

- Reason: Old bottle of $\mathrm{H}_{2} \mathrm{O}_{2}$ or inactive POD-conjugated antibody.

- Solution: Increase $\mathrm{H}_{2} \mathrm{O}_{2}$ concentration or use a fresh bottle. Use a fresh aliquot of the POD-conjugated antibody.

- Problem: Non-specific signal detectable in 2 imaging channels.

$\circ$ Reason 1: Wrong filters used or fluorophores spectrally too close.

- Solution 1: Use the right filters and spectrally well separated fluorophores.

- Reason 2: Sodium azide quench of previous POD-antibody omitted.

- Solution 2: Make sure to inactivate residual POD activity using sodium azide.

- Problem: Speckles, "bright glow" of the well surface and non-specific signal in "streaks" along the well.

○ Reason 1: Antibody blocking sub-optimal or omitted.

- Solution 1: Optimize blocking buffer for antibodies and/or increase concentration of RWBR.

- Reason 2: Too much antibody or riboprobe used.

- Solution 2: Titrate riboprobe and/or antibody concentrations.

- Reason 3: Riboprobe not properly purified.

- Solution 3: Repurify riboprobe (difficult) or prepare fresh clean riboprobe.

- Problem: No nuclear DAPI signal after BrdU staining.

$\circ$ Reason: DNA hydrolyzed by too long $\mathrm{HCl}$ antigen retrieval or too concentrated $\mathrm{HCl}$.

- Solution: Optimize antigen retrieval times for $\mathrm{BrdU}$ and use right $\mathrm{HCl}$ concentration.

- Problem: Bright autofluorescence in DAPI channel after BrdU staining.

$\circ$ Reason: Storage of BrdU stained cells in DABCO containing storage medium.

- Solution: Repeat the experiment or stain nuclei using DRAQ5 and image in the far red channel (if channel is free).

\section{Acknowledgements}

We thank the Rinklab for comments and specifically Albert Thommen for establishing the initial cell dissociation protocol and Hanh Thi-Kim Vu for technical advice on tyramide and riboprobe synthesis as well as helpful suggestions throughout the establishment of this method. Furthermore, we thank Marc Bickle, Martin Stöter and the team of the Technology Development Studio (TDS) at MPI CBG for help with imaging and automation.

\section{Bibliography}

Berlier, J E, A Rothe, G Buller, J Bradford, D R Gray, B J Filanoski, W G Telford, et al. 2003. "Quantitative Comparison of Long-Wavelength Alexa Fluor Dyes to Cy Dyes: Fluorescence of the Dyes and Their Bioconjugates." Journal of Histochemistry \& 
Cytochemistry 51 (12): 1699-1712. https://doi.org/10.1177/002215540305101214.

Boutros, Michael, Florian Heigwer, and Christina Laufer. 2015. "Microscopy-Based

High-Content Screening." Cell 163 (6): 1314-25.

https://doi.org/10.1016/j.cell.2015.11.007.

Brown, D, J Lydon, M McLaughlin, A Stuart-Tilley, R Tyszkowski, and S Alper. 1996. "Antigen

Retrieval in Cryostat Tissue Sections and Cultured Cells by Treatment with Sodium Dodecyl Sulfate (SDS)." Histochemistry and Cell Biology 105 (4): 261-67.

https://doi.org/10.1007/BF01463929.

Brown, David D. R., and Bret J. Pearson. 2015. "One FISH, DFISH, Three FISH: Sensitive

Methods of Whole-Mount Fluorescent In Situ Hybridization in Freshwater Planarians." In

In Situ Hybridization Methods, edited by Giselbert Hauptmann, 99:127-50.

Neuromethods. New York, NY: Springer New York.

https://doi.org/10.1007/978-1-4939-2303-8_7.

Burnett, W V. 1997. "Northern Blotting of RNA Denatured in Glyoxal without Buffer

Recirculation." Biotechniques 22 (4): 668-71.

Cheng, Li-Chun, and Alejandro Sánchez Alvarado. 2018. "Whole-Mount BrdU Staining with

Fluorescence In Situ Hybridization in Planarians." Methods in Molecular Biology 1774:

423-34. https://doi.org/10.1007/978-1-4939-7802-1_15.

Collins, Andrew M. 2016. "IgG Subclass Co-Expression Brings Harmony to the Quartet Model of Murine IgG Function." Immunology and Cell Biology 94 (10): 949-54. https://doi.org/10.1038/icb.2016.65.

David, Charles N. 1973. "A Quantitative Method for Maceration of Hydra Tissue." Wilhelm Roux' Archiv Fur Entwicklungsmechanik Der Organismen 171 (4): 259-68. https://doi.org/10.1007/BF00577724.

Fernandéz-Taboada, Enrique, Sören Moritz, Dagmar Zeuschner, Martin Stehling, Hans R Schöler, Emili Saló, and Luca Gentile. 2010. "Smed-SmB, a Member of the LSm Protein Superfamily, Is Essential for Chromatoid Body Organization and Planarian Stem Cell Proliferation." Development 137 (7): 1055-65. https://doi.org/10.1242/dev.042564.

Giloh, H, and J W Sedat. 1982. "Fluorescence Microscopy: Reduced Photobleaching of Rhodamine and Fluorescein Protein Conjugates by n-Propyl Gallate." Science 217 (4566): 1252-55. https://doi.org/10.1126/science.7112126.

Grohme, Markus Alexander, Siegfried Schloissnig, Andrei Rozanski, Martin Pippel, George Robert Young, Sylke Winkler, Holger Brandl, et al. 2018. "The Genome of Schmidtea Mediterranea and the Evolution of Core Cellular Mechanisms." Nature 554 (7690): 56-61. https://doi.org/10.1038/nature25473.

Hattori, Miki, Mai Miyamoto, Kazutaka Hosoda, and Yoshihiko Umesono. 2018. "Usefulness of Multiple Chalk-Based Food Colorings for Inducing Better Gene Silencing by Feeding RNA Interference in Planarians." Development, Growth \& Differentiation 60 (1): 76-81. https://doi.org/10.1111/dgd.12413.

Hauri, H P, and K Bucher. 1986. "Immunoblotting with Monoclonal Antibodies: Importance of the Blocking Solution." Analytical Biochemistry 159 (2): 386-89.

https://doi.org/10.1016/0003-2697(86)90357-x.

Hausen, P, and C Dreyer. 1982. "Urea Reactivates Antigens in Paraffin Sections for Immunofluorescent Staining." Stain Technology 57 (5): 321-24. https://doi.org/10.3109/10520298209066731.

Havemeyer, R N. 1966. "Freezing Point Curve of Dimethyl Sulfoxide--Water Solutions." Journal of Pharmaceutical Sciences 55 (8): 851-53. https://doi.org/10.1002/jps.2600550822. 
Hayashi, Tetsutaro, Maki Asami, Sayaka Higuchi, Norito Shibata, and Kiyokazu Agata. 2006. "Isolation of Planarian X-Ray-Sensitive Stem Cells by Fluorescence-Activated Cell Sorting." Development, Growth \& Differentiation 48 (6): 371-80. https://doi.org/10.1111/j.1440-169X.2006.00876.x.

Haycock, J W. 1993. "Polyvinylpyrrolidone as a Blocking Agent in Immunochemical Studies." Analytical Biochemistry 208 (2): 397-99. https://doi.org/10.1006/abio.1993.1068.

Hopman, A H, F C Ramaekers, and E J Speel. 1998. "Rapid Synthesis of Biotin-, Digoxigenin-, Trinitrophenyl-, and Fluorochrome-Labeled Tyramides and Their Application for In Situ Hybridization Using CARD Amplification." The Journal of Histochemistry and Cytochemistry 46 (6): 771-77. https://doi.org/10.1177/002215549804600611.

Hughes, Laura D, Robert J Rawle, and Steven G Boxer. 2014. "Choose Your Label Wisely: Water-Soluble Fluorophores Often Interact with Lipid Bilayers." Plos One 9 (2): e87649. https://doi.org/10.1371/journal.pone.0087649.

Johnson, G D, R S Davidson, K C McNamee, G Russell, D Goodwin, and E J Holborow. 1982. "Fading of Immunofluorescence during Microscopy: A Study of the Phenomenon and Its Remedy." Journal of Immunological Methods 55 (2): 231-42. https://doi.org/10.1016/0022-1759(82)90035-7.

King, Ryan S, and Phillip A Newmark. 2013. "In Situ Hybridization Protocol for Enhanced Detection of Gene Expression in the Planarian Schmidtea Mediterranea." BMC Developmental Biology 13 (March): 8. https://doi.org/10.1186/1471-213X-13-8.

Langanger, G, J De Mey, and H Adam. 1983. "[1,4-Diazobicyclo-(2,2,2)-Octane (DABCO) Retards the Fading of Immunofluorescence Preparations]." Mikroskopie 40 (7-8): 237-41.

Lauter, Gilbert, Iris Söll, and Giselbert Hauptmann. 2011. "Multicolor Fluorescent in Situ Hybridization to Define Abutting and Overlapping Gene Expression in the Embryonic Zebrafish Brain." Neural Development 6 (April): 10. https://doi.org/10.1186/1749-8104-6-10.

Ligasová, Anna, Petr Konečný, Ivo Frydrych, and Karel Koberna. 2017. "Looking for Ugly Ducklings: The Role of the Stability of BrdU-Antibody Complex and the Improved Method of the Detection of DNA Replication." Plos One 12 (3): e0174893. https://doi.org/10.1371/journal.pone.0174893.

Ligasová, Anna, Radek Liboska, Ivan Rosenberg, and Karel Koberna. 2015. "The Fingerprint of Anti-Bromodeoxyuridine Antibodies and Its Use for the Assessment of Their Affinity to 5-Bromo-2'-Deoxyuridine in Cellular DNA under Various Conditions." Plos One 10 (7): e0132393. https://doi.org/10.1371/journal.pone.0132393.

Manning, Colleen F, Angeliki M Bundros, and James S Trimmer. 2012. "Benefits and Pitfalls of Secondary Antibodies: Why Choosing the Right Secondary Is of Primary Importance." Plos One 7 (6): e38313. https://doi.org/10.1371/journal.pone.0038313.

Martin, R M, J L Brady, and A M Lew. 1998. "The Need for IgG2c Specific Antiserum When Isotyping Antibodies from C57BL/6 and NOD Mice." Journal of Immunological Methods 212 (2): 187-92. https://doi.org/10.1016/s0022-1759(98)00015-5.

Masek, Tomas, Vaclav Vopalensky, Petra Suchomelova, and Martin Pospisek. 2005. "Denaturing RNA Electrophoresis in TAE Agarose Gels." Analytical Biochemistry 336 (1): 46-50. https://doi.org/10.1016/j.ab.2004.09.010.

Moritz, Sören, Franziska Stöckle, Claudia Ortmeier, Henning Schmitz, Gustavo Rodríguez-Esteban, Göran Key, and Luca Gentile. 2012. "Heterogeneity of Planarian Stem Cells in the S/G2/M Phase." The International Journal of Developmental Biology 
56 (1-3): 117-25. https://doi.org/10.1387/ijdb.113440sm.

Nadin-Davis, S, and V A Mezl. 1982. "Optimization of the Ethanol Precipitation of RNA from Formamide Containing Solutions." Preparative Biochemistry 12 (1): 49-56.

https://doi.org/10.1080/00327488208065549.

Ouannes, Catherine., and Therese. Wilson. 1968. "Quenching of Singlet Oxygen by Tertiary Aliphatic Amines. Effect of DABCO (1,4-Diazabicyclo[2.2.2]Octane)." Journal of the American Chemical Society 90 (23): 6527-28. https://doi.org/10.1021/ja01025a059.

Panchuk-Voloshina, N, R P Haugland, J Bishop-Stewart, M K Bhalgat, P J Millard, F Mao, W Y Leung, and R P Haugland. 1999. "Alexa Dyes, a Series of New Fluorescent Dyes That Yield Exceptionally Bright, Photostable Conjugates." Journal of Histochemistry \& Cytochemistry 47 (9): 1179-88. https://doi.org/10.1177/002215549904700910.

Pearson, Bret J, George T Eisenhoffer, Kyle A Gurley, Jochen C Rink, Diane E Miller, and Alejandro Sánchez Alvarado. 2009. "Formaldehyde-Based Whole-Mount in Situ Hybridization Method for Planarians." Developmental Dynamics 238 (2): 443-50. https://doi.org/10.1002/dvdy.21849.

Peränen, J, M Rikkonen, and L Kääriäinen. 1993. "A Method for Exposing Hidden Antigenic Sites in Paraformaldehyde-Fixed Cultured Cells, Applied to Initially Unreactive Antibodies." The Journal of Histochemistry and Cytochemistry 41 (3): 447-54. https://doi.org/10.1177/41.3.8429208.

Reddien, Peter W, Néstor J Oviedo, Joya R Jennings, James C Jenkin, and Alejandro Sánchez Alvarado. 2005. "SMEDWI-2 Is a PIWI-like Protein That Regulates Planarian Stem Cells." Science 310 (5752): 1327-30. https://doi.org/10.1126/science.1116110.

Rio, Donald C. 2015. "Denaturation and Electrophoresis of RNA with Formaldehyde." Cold Spring Harbor Protocols 2015 (2): 219-22. https://doi.org/10.1101/pdb.prot080994.

Rouhana, Labib, Jennifer A Weiss, David J Forsthoefel, Hayoung Lee, Ryan S King, Takeshi Inoue, Norito Shibata, Kiyokazu Agata, and Phillip A Newmark. 2013. "RNA Interference by Feeding in Vitro-Synthesized Double-Stranded RNA to Planarians: Methodology and Dynamics." Developmental Dynamics 242 (6): 718-30. https://doi.org/10.1002/dvdy.23950.

Smith, P J, M Wiltshire, S Davies, L H Patterson, and T Hoy. 1999. "A Novel Cell Permeant and Far Red-Fluorescing DNA Probe, DRAQ5, for Blood Cell Discrimination by Flow Cytometry." Journal of Immunological Methods 229 (1-2): 131-39. https://doi.org/10.1016/S0022-1759(99)00116-7.

Thisse, Christine, and Bernard Thisse. 2008. "High-Resolution in Situ Hybridization to Whole-Mount Zebrafish Embryos." Nature Protocols 3 (1): 59-69. https://doi.org/10.1038/nprot.2007.514.

Thommen, Albert, Steffen Werner, Olga Frank, Jenny Philipp, Oskar Knittelfelder, Yihui Quek, Karim Fahmy, et al. 2019. "Body Size-Dependent Energy Storage Causes Kleiber's Law Scaling of the Metabolic Rate in Planarians." ELife 8 (January). https://doi.org/10.7554/eLife.38187.

Vogt, R F, D L Phillips, L O Henderson, W Whitfield, and F W Spierto. 1987. "Quantitative Differences among Various Proteins as Blocking Agents for ELISA Microtiter Plates." Journal of Immunological Methods 101 (1): 43-50.

Wagner, Daniel E, Irving E Wang, and Peter W Reddien. 2011. "Clonogenic Neoblasts Are Pluripotent Adult Stem Cells That Underlie Planarian Regeneration." Science 332 (6031): 811-16. https://doi.org/10.1126/science.1203983. 